\title{
Asset Prices and Rents in a GE Model with Imperfect Competition
}

\author{
Pierre Lafourcade * \\ Board of Governors of the Federal Reserve System
}

November 14, 2003

\begin{abstract}
This paper analyses the general equilibrium effects on asset valuation and capital accumulation of an exogenous drop in the rate of return required by investors in a model of production with imperfectly competitive product markets. The model improves substantially on the standard perfectly competitive neo-classical framework, by dissociating the behavior of marginal and average q. It tracks more closely current observed data on the ratio of stock-market value to the economy's capital base, while uncoupling this valuation ratio from investment behavior. The model does so by assuming that asset holders price not only the future marginal productivity of capital, but also the value of monopoly franchises, which arise from the interplay of market power and returns to scale.
\end{abstract}

JEL Classification: G00, E20.

Keywords: Asset pricing, investment, monopolistic competition, markups, scale.

\footnotetext{
*Address: Federal Reserve Board, Washington, DC, 20551. E-mail:pierre.lafourcade@frb.gov. The author would like to thank Gernot Doppelhofer, Jayasri Dutta, Petra Geraats, Peter Tinsley, Stephen Wright and participants at seminars in Cambridge, Birmingham, Munich and the Federal Reserve Board for helpful comments. The views presented in this paper are solely the author's and do not necessarily represent those of the Federal Reserve Board or its staff.
} 


\section{Introduction}

Considerable attention has been devoted to understanding the basis of the run-up in the US stock market in the late 1990s, when price-dividend ratios reached levels unseen since the early part of the century. The natural framework in which to study the drivers of this financial indicator - and indeed of most ratios of asset price to a measure of income flow - is the dividend discount model. This framework suggests that elevated ratios are a consequence of an increase in the growth rate of productivity, a drop in the rate of return required by investors or, what many observers believe was the major explanation of the bull run of the 1990s, an expectational bubble.

However, the temptation to analyse stock market movements through the lens of this model often leads to a fallacy of composition, namely making misleading inferences at an aggregate level from a partial equilibrium setting. This fallacy arises for two reasons. First, although the rate at which profits are discounted is typically exogenous for an individual firm, it is not so at the aggregate level, as the prevailing rate will depend on the desired intertemporal consumption profile of consumers, who are the ultimate owners of the firms. The higher the expected growth rate of future consumption, the higher the required return must be for investors to save. Second, the dividend discount valuation formula in its simplest form fails to take into account the fact that firms must finance capital deepening by reducing dividends. A lower required return increases the firms' investment opportunities which are funded by retained earnings at the expense of the residual claimants. In other words, dividends, returns and growth rates are all inter-related. Hence the warrant for a general equilibrium model of asset pricing with production.

Kiley (2000) argued against the widespread interpretation (at the time) of the bull run as stemming from an exogenous drop in the equity premium. He analysed the asset pricing implications of a drop in the rate of return required by investors, both in a calibrated neoclassical growth model and in the dividend discount model. He concluded that the latter model will overstate the equity valuation effects by a substantial amount: the drop in the required return that justifies valuation levels in the dividend discount model falls short of explaining them in a general equilibrium setting. Moreover, such a drop in the required return has theoretical implications for fundamentals, especially investment, which do not seem to be borne 
out in the data. Investment in the 1990s, despite its cyclical pick-up, does not appear as responsive as expected given the increased opportunities generated by the drop in the return (Bond and Cummins (2000, 2001) provide empirical support to Kiley on this point).

This result begs the question: how far does plausibility in calibration have to be stretched in order to justify observed valuations with a general equilibrium model that retains the rational agents hypothesis? This paper attempts to flesh out the asset pricing consequencesqualitative and quantitative - of introducing imperfectly competitive product markets into such a framework. There are two main reasons why this exercise may yield interesting conclusions for the present purpose of explaining valuation movements.

First, there exists a large body of literature, stemming from Hall's (1990) seminal analysis of pro-cyclical Solow residuals, which has ground through both the theory of imperfect competition and increasing returns to scale (see among many others Rotemberg and Woodford (1999), Farmer (1999) and references therein) and the empirics of scale effects and industry markups (for example, Domowitz, Hubbard and Peterson (1988), Baxter and King (1991), Caballero and Lyons (1992), Basu and Fernald (1995, 1997), or lately, Altug and Filiztekin (2001)). As this literature makes clear, the paradigm of imperfect competition adds three dimensions to the standard general equilibrium model. Markups and fixed costs affect the equilibrium values of the system as well as the transition path to the system's new steadystate. They may also enhance the impact of other exogenous parameters on macroeconomic variables. Third, they may change the predicted direction of this impact. Therefore, it seems reasonable that, if there exists any link between valuation and fundamentals, it should be sensitive to the specification of the competitive environment.

Second, the natural valuation indicator to use in a framework with production is average $q$, the ratio of stock price to the firm's capital base. This ratio has the virtue of making explicit the dividend process. ${ }^{1}$ Moreover, it serves precisely as the link between valuation and fundamentals in a general equilibrium model. From the dynamic optimisation problem of a firm with convex costs of capital adjustment, average $q$ can proxy the shadow price of capital, marginal $q$, the unobservable but critical variable which completely summarizes investment behavior. However, this equivalence, demonstrated by Hayashi (1982), occurs

\footnotetext{
${ }^{1}$ Rewriting it $q=\frac{V}{D} \cdot \frac{D}{K}$, it captures not only movements in the price-dividend ratio $\frac{V}{D}$, but also in the corporate payout rate $\frac{D}{K}$ (expressed per unit of capital).
} 
only under some stringent assumptions, namely homogeneity of the profit and adjustment cost functions. Introducing imperfect competition is a straightforward way of relaxing these assumptions. Although Hayashi showed analytically how the equivalence breaks down when firms exert market power, he did so while maintaining the assumption of constant returns to scale. Rather, this paper emphasizes that the dissociation between marginal and average $q$ actually depends on the ratio of the degrees of prevailing market power and returns to scale, and exploits this fact in a calibration exercise. Intuitively, the value of equity should reflect not only the firm's capital base but also its monopolistic advantage in extracting rents. In other words, this paper questions the traditional assumption in the business cycle literature, that there are no pure monopoly profits. The possible existence of pure profits implies that although marginal $q$ may be a sufficient statistic for investment, its proxy may capture changes in the competitive environment, thus blurring the statistical link between valuation and fundamentals.

Uncoupling these two measures of capital value is not a novel idea. Summers (1981) is an early example, where the wedge comes from tax purposes. ${ }^{2}$ Changes in tax rates in RBC models have powerful effects on real activity by inducing substitutions across goods and time that affect labor supply and investment choices (see Prescott (2002) for a recent exposition of this point). Viewed from optimality conditions that equate marginal rates of substitution to after-tax relative prices, tax changes operate like technology shocks. ${ }^{3}$ From the slightly different angle of monopolistic competition, however, markups are analogous to tax rates, but of a potentially much more volatile form. This is the driving idea of the paper: to use markups to investigate whether the observed data for average $q$ is consistent with investment behavior witnessed in the past few years. In short, what Kiley (and countless others) have called a bubble may have been the rational response of agents to a combination of technology and markup shocks moving in a given direction.

The paper is organized as follows. The second section sets up the model with imperfect

\footnotetext{
${ }^{2}$ More recent examples are Licandro (1992) and Fagnart, Licandro and Portier (1999), where the wedge arises from variable capacity utilisation, and the emphasis is on the role of excess capacity on magnification and persistence of technology shocks in the business cycle.

${ }^{3}$ Interestingly, Kiley mentions in his paper, as a passing comment, that taxes could indeed drive a more complicated dynamic system for stock values and shadow prices of capital, but that the tax code has not changed sufficiently in the past ten years to justify a calibrated analysis of its impact on the stock market.
} 
competition. The third section analyses the quantitative implications of a drop in the return required by investors and of a change in prevailing markups on asset prices in the calibrated model. The fourth section extends the model with an entry condition which governs the longrun behaviour of monopoly franchises. The fifth section discusses extensions and concludes.

\section{A General Equilibrium Model with Imperfect Competition}

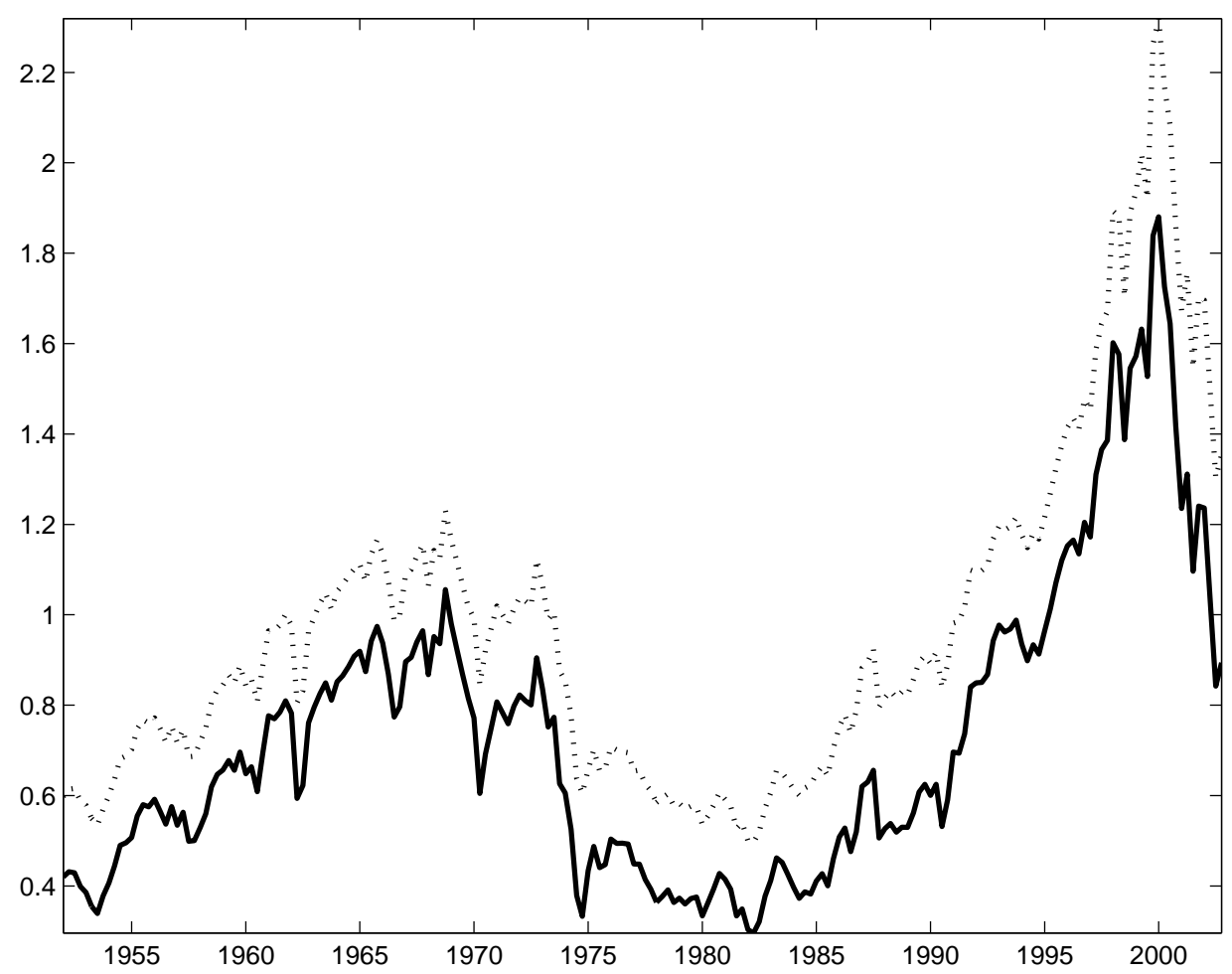

Figure 1: Average $q$ - ratio of equity to net worth (solid) and of market value to tangible assets (dotted) (US quarterly data)

Figures 1 and 2 plot the time series for average $q$ in the non-financial non-farm business sector and the ratio of gross non-residential private fixed investment to the gross domestic output of non-farm business. ${ }^{4}$ The value of average $q$ in the late 1990s was historically

\footnotetext{
${ }^{4}$ Data for average $q$ is taken from the Flow of Funds accounts of the Federal Reserve Board. The solid line is the ratio of market value of equities outstanding (line 34 on table B.102) to the replacement value of net worth (line 31). The dotted line is the ratio of the market value of the firm, which is the sum of credit market instruments (line 21) and the market value of equities outstanding (line 34), divided by the value of reproducible assets, the best guess of which is tangible assets (line 2). These two measures are quite clearly very similar (apart from the level shift), and are both widely-used indicators on Wall Street (see Robertson
} 


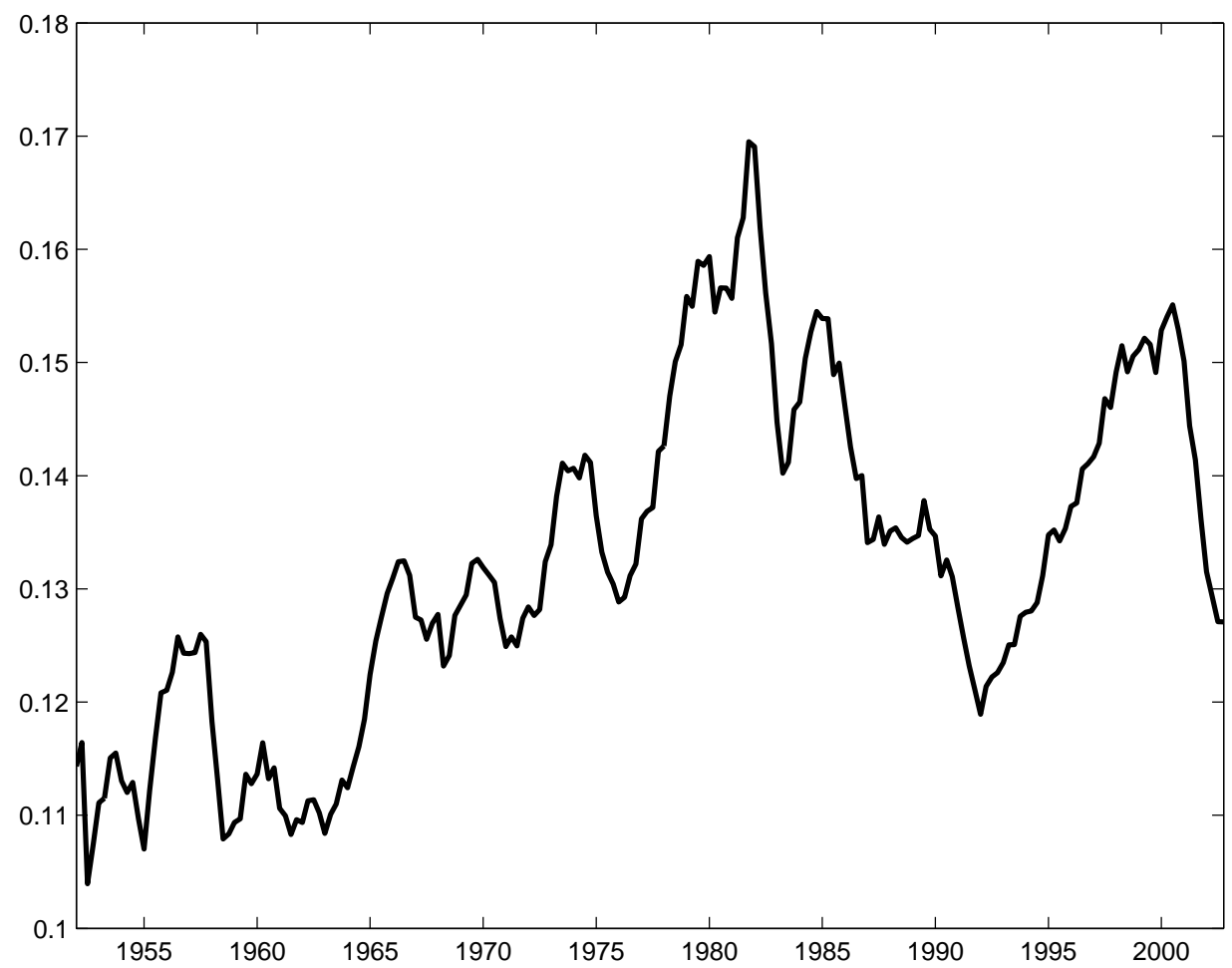

Figure 2: Nominal investment-output ratio (US quarterly data)

unprecedented, while investment behavior (relative to output) remained within its post-war range. The magnitude of $q$ in the late 1990s and the divergence between these two series throughout the sample period are the two stylized facts of interest in this paper.

The general equilibrium model used by Kiley (2000) is a discrete-time, stochastic version with labor-leisure choice of the deterministic, continuous time model developed in Abel and Blanchard (1983). I return to the latter model, however, and combine it with the Rotemberg and Woodford (1995) version of monopolistic competition, as it is easier to manipulate for the simple calibration exercise this paper will pursue. By doing so, two questions arise which will be dealt with in time. The first is in the modelling of the equity premium (which technically does not appear in a deterministic model), and the second is the implication of labor supply decisions on the dynamics of the system in the presence of increasing returns.

The model assumes a continuum of producers-consumers over $[0,1]$ who maximize utility

and Wright (2002a) for a fuller discussion of the conceptual issues underlying these definitions). Data for the nominal investment-output ratio is taken from Tables 1.7 and 5.4 of the quarterly NIPA tables, available at http://www.bea.doc.gov/bea/dn/nipaweb/AllTables.asp. 
of consumption for given constraints on their spending patterns. The production side of the economy consists of two sectors, a monopolistically competitive sector producing differentiated goods, which are sold to a competitive sector which produces a final good. This good is used in turn for final consumption and production of intermediate inputs. Firms buy materials, invest, hire labor, pay wages, sell their product and make a profit which they distribute to consumers in proportion to their share holdings. The competitive sector produces the final good from intermediate inputs purchased from the household firms at given prices. Labor is supplied inelastically. Individual optimal conditions are derived and aggregated to the economy-wide level by restricting attention to symmetric equilibria. Since consumers and firms care only for the composite good, and capital and labor markets are assumed to be perfectly competitive, one can study the behavior of a single household as representative of that of the aggregate economy.

\subsection{Consumer behavior}

Formally, the consumer solves the following problem

$$
\max _{\{c(t)\}} \int_{0}^{\infty} e^{-\rho t} u(c(t)) d t
$$

subject to

$$
\dot{b}(t)+\int_{0}^{1} v(t, z) \dot{x}(t, z) d z+c(t)=\int_{0}^{1} d(t, z) x(t, z) d z+w(t) n(t)+r(t) b(t)
$$

where $b$ is real bond holdings, $r$ the interest they carry, $w n$ the wage bill, $v(z)$ is the real value of firm $z$ 's equity, $x(z)$ is the share of that equity held by the consumer, and $d(z)$ is the real dividend paid. Labor is assumed to be supplied inelastically, and does not come into the agent's decision problem. The utility function is CRRA with coefficient of risk aversion $\gamma: u(c(t))=\frac{c(t)^{1-\gamma}-1}{1-\gamma}$. The following first order conditions are obtained from the Hamiltonian:

$$
\begin{aligned}
\gamma \frac{\dot{c}(t)}{c(t)} & =r(t)-\rho, \\
\frac{\dot{v}(t, z)+d(t, z)}{v(t, z)} & =r(t),
\end{aligned}
$$


to which is associated the standard transversality condition

$$
\lim _{s \rightarrow \infty} R(t, s) v(s, z)=0
$$

where $R(t, s) \equiv \exp \left(-\int_{t}^{s} r(u) d u\right)$ is the compound discount rate between time $t$ and $s$. The first equation is the standard consumption Euler equation. The second is the arbitrage equation between rates of return of the two assets. Solving this last differential equation yields

$$
v(t, z)=\int_{t}^{\infty} R(t, s) d(s, z) d s
$$

That is, the value of firm $z$ is the present discounted value of its future dividends.

\subsection{Firm behavior}

\subsubsection{Final good production}

Each household $z$ produces a single good $y(z) .{ }^{5}$ This good is used as an intermediate input for the production of a composite good $y$ using the following technology

$$
y=\left[\int_{0}^{1} y(z)^{\theta} d z\right]^{\frac{1}{\theta}}, \quad \theta<1 .
$$

In turn, this good is sold back to households and firms as consumption $c$ and production goods (investment $i$ and materials $m$ ), that is

$$
y=\int_{0}^{1}(c(z)+i(z)+m(z)) d z=c+i+m .
$$

In other words, the technology in the final good sector is simply Dixit and Stiglitz's (1977) aggregator; it does not involve capital or labor, and exhibits constant returns to scale. Potential profits are determined by

$$
p y-\int_{0}^{1} p(z) y(z) d z
$$

\footnotetext{
${ }^{5}$ For expositional convenience, this subsection drops time-indexing, as there is no ambiguity about timedependency in this otherwise standard framework.
} 
where $p(z)$ is the price of good $z$, and $p$ is the general price index, which is used for deflating nominal variables. Maximising this expression by choice of either output $y(z)$ or price $p(z)$ leads to a demand schedule for inputs of the form

$$
\frac{p(z)}{p}=\left[\frac{y(z)}{y}\right]^{\theta-1}
$$

but free entry in the final good sector eliminates these profits, yielding an expression for the price of the composite good

$$
p=\left[\int_{0}^{1} p(z)^{\frac{\theta}{\theta-1}} d z\right]^{\frac{\theta-1}{\theta}} .
$$

Clearly, this aggregating device is used to produce single-good analogues of output, consumption, investment and material goods from a concept of differentiated goods. With a single aggregator, these composite goods are assumed to use the same mix of intermediate commodities. The parameter $\theta$ measures both the slope of the demand curve for each good and the cross-elasticity of substitution. The limiting case of $\theta=1$ reflects a perfectly competitive environment due to perfect substitutability between goods.

\subsubsection{Intermediate good production}

Firms create intermediate goods using a production process that combines capital, labor and materials, and benefits from labor-augmenting technological progress. In the spirit of Rotemberg and Woodford (1995), the production process takes the functional form

$$
Q(z)=\min \left[\frac{y(z)}{1-s_{m}}, \frac{m(z)}{s_{m}}\right]
$$

where $y(z)$ is the value-added created by firm z, and $s_{m} \equiv \frac{m}{Q}$ is the share of material costs in gross output $Q$. Thus, the left-hand argument of the minimand is a production function for value-added $y \equiv Q-m$ that is independent of market power and a fixed proportion $1-s_{m}$ of gross output. Throughout the paper, $s_{m}$ is taken as a structural parameter of the model. Its importance will be clear later.

The reason Rotemberg and Woodford use the Leontief technology is the following. In a competitive setting, production functions usually omit materials as an argument. This is 
because the output measure of relevance is value-added, the difference between production of goods and the cost of materials used for it. Under perfect competition, since materials and output have the same price, the demand schedule for the former can be re-written as a relationship between value-added and capital and labor. ${ }^{6}$ However, in this framework, firms face a downward-sloping demand schedule for their product, and therefore exert pricing power in their relevant market which feeds back into the demand schedule for materials. The fixed coefficent technology insulates this schedule from the degree of market power.

I depart from Rotemberg and Woodford's framework by adding a cost to installing capital, so as to dissociate the value of the firm from the value of the capital that it owns. Value-added (which is the analog of GDP in the data) takes the form

$$
y=f(k, A n, i)-\Phi=k^{\alpha}(A n)^{1-\alpha}-h(i, k)-\Phi,
$$

where $k$ is the firm's capital input, $n$ its labor input, $A$ a Harrod-neutral technology parameter, $\Phi$ are fixed costs and $h(i, k)$ is a constant returns to scale capital installation cost function. The returns to scale index for value added is

$$
\eta=\frac{\frac{d y}{d k} k+\frac{d y}{d A n} A n+\frac{d y}{d i} i}{y}=\frac{f_{k} k+f_{A n} A n+f_{i} i}{f-\Phi}=\frac{f}{f-\Phi} \geq 1
$$

so that value-added can be written as

$$
y=\frac{f}{\eta} .
$$

As will be made clear in the next subsection, fixed costs are necessary to justify the absence of pure profits in the steady-state of an economy with market power. With a downward-sloping demand curve, price exceeds marginal cost, but with increasing returns, so does average cost, and pure profits are zero precisely when price equals average cost. To rationalize these fixed costs, one can imagine them representing a cost in resources to produce goods or install capital each period (see Rotemberg and Woodford (1999) for other interpretations of fixed costs, such as the presence of overhead labor).

\footnotetext{
${ }^{6}$ Under perfect competition, if output of the good is $Q=g(k, n, m)$, value-added is $Q-m=$ $\max _{m}(g(k, n, m)-m)=f(k, n)$.
} 


\subsection{Optimality}

Dividends are deflated by the price index, and represent the residual from output sales once labor has been paid. That is, for household $z$,

$$
d(t, z)=\frac{p(t, z)}{p(t)} Q(t, z)-w(t) n(t)-i(t, z)-m(t, z)
$$

The firm wishes to maximize the value of its equity (3) subject to the constraints (6), (4), (8), and the capital accumulation equation $\dot{k}(t, z)=i(t, z)-\delta k(t, z)$. From here on, to avoid cluttering of indices, both the $t$ 's and the $z$ 's are dropped when unambiguously convenient. In any case, the latter will disappear in the symmetric equilibrium where $p(z)=p$. Setting up the Hamiltonian and solving for the control variables $n, i, p(z)$ and the state variable $k$ yields the following:

$$
\begin{aligned}
w & =\lambda f_{n}(k, A n, i) \\
q & =1-\lambda f_{i}(k, A n, i)=1+\lambda h_{i}(i, k) \\
\dot{q} & =(r+\delta) q-\lambda f_{k}(k, A n, i) \\
\lambda & =\frac{\theta \frac{p(z)}{p}-s_{m}}{1-s_{m}}=\frac{\theta-s_{m}}{1-s_{m}}
\end{aligned}
$$

and the transversality condition $\lim _{s \rightarrow \infty} R(t, s) q(s) k(s)=0$. Here, $q$ is the costate variable on the investment condition for any firm $z$ (and as such represents the shadow price of its capital), and $\lambda$ is the Lagrange multiplier on the definition of value-added (equation (6)). The firm's markup, the ratio of output price to marginal cost, is $\frac{1}{\theta}$, but the 'value-added markup', the ratio between the price of value-added and its marginal cost, is

$$
\mu \equiv \frac{1}{\lambda}=\frac{\left(1-s_{m}\right) \frac{1}{\theta}}{1-s_{m} \frac{1}{\theta}}
$$

which is greater than the markup $\frac{1}{\theta}$ when $s_{m}>0$, because firms mark up their material inputs as well (see Rotemberg and Woodford (1995)). As these authors emphasize, the presence of materials is important in understanding the variation in measures of market power found in the empirical literature, as some studies attempt to measure the value-added markup $\mu$ and 
others the elasticity of demand $\theta$.

Substituting the optimality conditions into the definition of value-added in equation (6), one obtains

$$
\begin{aligned}
\eta y & =\mu(w n+(1-q) i+[(r+\delta) q-\dot{q}] k) \\
\left(1-\frac{\eta}{\mu}\right) y & =y-(w n+(1-q) i+[(r+\delta) q-\dot{q}] k)
\end{aligned}
$$

This last term represents pure monopoly profits, the difference between total revenue and total cost. Pure profits are zero (price equals average cost) when returns to scale (ratio of average cost to marginal cost) exactly offset the markup (ratio of price to marginal cost). The term on the left-hand side, $1-\eta \mu^{-1}$, is the share of pure monopoly profits, equal to 1 (the price of the goods in units of output) minus real average cost. Denote $\pi \equiv \mu \eta^{-1}$ as the inverse of real average cost. Clearly $\pi$ is a monotonic transformation of the pure profit share, and I will use the two terms interchangeably in what follows.

Most of the literature assumes that there are never any pure profits to be made. This paper takes the different view that there is no particular reason to suppose $\mu=\eta$ at all points in time. Relaxing this assumption is the key to the central result of the paper. Multiplying (11) by $k$, and using the homogeneity assumption on $f$, one obtains:

$$
\begin{aligned}
\dot{q} k & =(r+\delta) q k-\lambda f_{k} . k \\
(\dot{q} \dot{k})-q \dot{k} & =(r+\delta) q k-\lambda\left(f-f_{i} . i-f_{n} . n\right) \\
(\dot{q} \dot{k}) & =q(i-\delta k)+(r+\delta) q k-\lambda f+(1-q) i-w n \\
& =r q k-\lambda f+i+w n \\
& =r q k+\left(1-\pi^{-1}\right) y-d .
\end{aligned}
$$

Eliminating $d$ with equation (2), this latter differential equation can be solved for by appealing to the two transversality conditions on the value of the two assets $v$ and $q k$, yielding

$$
v(t)=q(t) k(t)+\int_{t}^{\infty} R(t, s)\left(1-\pi^{-1}\right) y(s) d s .
$$

Therefore, the value of the firm is greater than the shadow value of its capital stock by the 
present discounted value of its future monopoly profits (if $\mu>\eta$ ). The intuition is that in the presence of market power, factor inputs are paid less than their marginal product. If this gap is greater than the amount necessary to cover the fixed costs inherent in production, then there is residual output that is not owed to any provider of input, and remains the property of the firm, which in turn is the property of its shareholders. Hence shares of the firm are a claim not only to its capital base but also to its monopoly franchise. Clearly, in the case of perfect competition and constant returns to scale, $\mu=\eta=1$, and Hayashi's (1982) result that average $q$ is equal to marginal $q$ is obtained. One can write this relationship in terms of the gap between the observed and shadow values of capital $\omega=v-q k$ :

$$
\dot{\omega}=r \omega-\left(1-\pi^{-1}\right) y
$$

\subsection{Equilibrium}

The economy's equilibrium conditions are summarized by equations $(1,6,9-12,15)$, the capital accumulation equation, the two transversality conditions, the asset market-clearing conditions that $x=1$ and $b=0$, and the pricing symmetry condition $p(z)=p$. To solve for the equilibrium, this system is re-written in 'per effective worker' terms, by dividing each relevant quantity variable by $A n$. With the homogeneity of the $f$ function, the transformed variables now satisfy

$$
\begin{aligned}
\gamma \frac{\dot{c}}{c} & =r-\rho-\gamma g, \\
\mu(q-1) & =-f_{i}(k, i), \\
\mu((r+\delta) q-\dot{q}) & =f_{k}(k, i), \\
y & =c+i, \\
\eta y & =f(k, i), \\
\dot{k}=i-(g+\delta) k & \\
\dot{\omega}=(r-g) \omega- & \left(1-\pi^{-1}\right) y,
\end{aligned}
$$


where $g$ is the growth rate of technology $g \equiv \frac{\dot{A}}{A}$. I assume no population growth. The balanced growth path is defined by the conditions that $\dot{k}=\dot{c}=\dot{q}=\dot{x}=0$, and aggregate capital, output, investment, and consumption all grow at rate $g$. The adjustment cost function is assumed to take the standard quadratic form,

$$
h(i, k)=\frac{\chi}{2} k\left(\frac{i}{k}-(g+\delta)\right)^{2}
$$

implying that there are no costs when the economy is on the balanced growth path. This path is characterized by the following relationships,

$$
\begin{gathered}
q^{*}=1, \\
f_{k}\left(k^{*}, i^{*}\right)=\mu\left(r^{*}+\delta\right), \\
\frac{i^{*}}{k^{*}}=g+\delta, \\
\omega^{*}=\frac{\left(1-\pi^{-1}\right)}{r^{*}-g} y^{*}, \\
\frac{y^{*}}{k^{*}}=\pi \frac{\left(r^{*}+\delta\right)}{\alpha}, \\
k^{*}=\left[\frac{\alpha}{\mu\left(r^{*}+\delta\right)}\right]^{\frac{1}{1-\alpha}},
\end{gathered}
$$

where $r^{*}=\rho+\gamma g$. The presence of market power causes the steady-state marginal product of capital to be sub-optimally high, and by extension the capital stock to be sub-optimally low. More importantly for this paper's purpose, it does not affect the equilibrium shadow price of capital (since investment is fungible with output by assumption, so that it must command the same price in equilibrium), but it does affect its average price, since

$$
\begin{aligned}
\frac{v^{*}}{k^{*}} & =q^{*}+\left(1-\pi^{-1}\right) \frac{1}{r^{*}-g} \frac{y^{*}}{k^{*}} \\
& =1+\frac{\pi-1}{\alpha} \frac{r^{*}+\delta}{r^{*}-g} .
\end{aligned}
$$

Notice that the required rate of return has two competing effects. Ceteris paribus, in particular for a constant markup over cost, a higher rate implies higher costs of using capital, hence 
proportionally higher pure profits (recall equation 13). In turn, a higher rate discounts these profits more heavily. The existence of even a small equilibrium pure profit share has large effects on the long-run value of average $q$. For example, a profit share of $3 \%$ of value-added, combined with the standard calibrated values of $r=7.5 \%, \delta=6 \%, \alpha=0.3$ and $g=2 \%$, yields an average $q$ of 1.25 . This arises because the discounting effect increases hyperbolically as the gap between the required return and the growth rate narrows. Later, a restriction will be added on entry and exit which ensures that pure profits are zero in the long-run, thus implying that $\frac{v^{*}}{k^{*}}=q^{*}=1$. For the time being, however, I take it that these profits are sustainable, and observe what implications this has for valuation.

Consider the parameter $\kappa \equiv\left(r^{*}+\delta\right)\left(r^{*}-g\right)^{-1}$, which captures the two competing effects of the interest rate. One can express both average $q$ and the investment-output ratio as a function of $\kappa$ and $\pi$ :

$$
\begin{aligned}
\frac{v^{*}}{k^{*}} & =1+\frac{\pi-1}{\alpha} \kappa, \\
\frac{i^{*}}{y^{*}} & =\frac{\alpha}{\pi}\left[1-\frac{1}{\kappa}\right] .
\end{aligned}
$$

It is useful at this stage to recall the aim of the model: explain how average $q$ can theoretically reach observed magnitudes without a corresponding swing in fundamentals (captured by the investment-output ratio), and more generally how the two series can be dissociated. Equations (24) and (25) point to the long-run qualitative results of the following calibration exercises. A change in $\kappa$-from a change in either $r$ or $g$-pushes both valuation and fundamentals in the same direction. Thus, from a steady-state perspective, explaining the valuation conundrum with $\kappa$ only compounds the fundamentals conundrum. However, a change in $\pi$ has opposite effects on average $q$ and the $i / y$ ratio and is therefore a potential explanation for the observed dissociation between the two series.

\subsection{Transitional dynamics}

It will be more telling to track the dynamics of $q^{\pi} \equiv \frac{\omega}{k}=\frac{v}{k}-q$ in what follows. Rearranging the relevant equation and Taylor-expanding the previous system around the equilibrium growth path yields the following equations, where the derivatives are evaluated at 
the steady-state, and the sans-serif variables are the deviations from equilibrium:

$$
\begin{aligned}
\mu \mathrm{q} & =h_{i i} \mathrm{i}+h_{i k} \mathrm{k}, \\
f_{k} \mathrm{k} & =\eta(\mathrm{c}+\mathrm{i}) \\
\dot{\mathrm{k}} & =\mathrm{i}-(g+\delta) \mathrm{k}, \\
\dot{\mathrm{q}} & =\frac{\gamma}{c^{*}} \dot{\mathrm{c}}+\left(r^{*}+\delta\right) \mathrm{q}-\frac{1}{\mu}\left(f_{k k} \mathrm{k}+f_{k i} \mathrm{i}\right), \\
\dot{\mathrm{q}}^{\pi} & =\left(r^{*}-g\right) \mathrm{q}^{\pi}+\frac{\gamma q^{\pi *}}{c^{*}} \dot{\mathrm{c}}-\frac{q^{\pi *}}{k^{*}} \dot{\mathrm{k}}-\left(1-\frac{\eta}{\mu}\right) \frac{f_{k}}{\eta k^{*}} \mathrm{k} .
\end{aligned}
$$

Equations (26-30) form a system of five equations in c, k, i, q, $\mathrm{q}^{\pi}$, which can be reduced to a system in $\mathrm{k}, \mathrm{q}$, and $\mathrm{q}^{\pi}$. Notice that this system generalizes the standard Jorgensonian model (the partial equilibrium analysis with constant interest rate, when $\gamma=0$ ) and Abel and Blanchard's (1983) model (perfect competition and constant returns to scale of both the production and adjustment cost functions, and $\mu=\eta=1$ ). The system can be written as

$$
\dot{X}=A X,
$$

where

$$
\begin{aligned}
X^{T} & =\left[\begin{array}{lll}
\mathrm{k} & \mathrm{q} & \mathrm{q}^{\pi}
\end{array}\right] \\
A & =\left[\begin{array}{ccc}
0 & \psi_{1} & 0 \\
-\frac{1}{\mu} \frac{f^{\prime \prime}\left(k^{*}\right)}{1+\xi} & \psi_{2} & 0 \\
\psi_{3} & \psi_{4} & r^{*}-g
\end{array}\right],
\end{aligned}
$$


and

$$
\begin{aligned}
\psi_{1} & =\frac{\mu k^{*}}{\chi}, \\
\xi & =\mu \frac{\gamma}{\chi} \frac{k^{*}}{c^{*}}, \\
\psi_{2} & =\left(r^{*}-g\right)\left(1+\alpha \frac{\xi}{1+\xi} \frac{q^{\pi *}}{k^{*}}\right)>0, \\
\psi_{3} & =(1-\alpha)\left[\left(r^{*}-g\right)-\frac{\xi}{1+\xi}\left(r^{*}+\delta\right)\right] \frac{q^{\pi *}}{k^{*}}, \\
\psi_{4} & =\alpha\left(r^{*}-g\right) \frac{\xi}{1+\xi} q^{\pi * 2}-\mu \frac{q^{\pi *}}{\chi} .
\end{aligned}
$$

Since the matrix is block-lower triangular, its eigenvalues are $r^{*}-g$ and the eigenvalues of the Abel-Blanchard system (in k, q space), which is saddlepath stable. Therefore, this system has a saddle-path equilibrium, since there are as many positive eigenvalues (two) as there are non-predetermined variables ( $\mathbf{q}$ and $\mathbf{q}^{\pi}$ ). Take $\lambda_{1}<0$. The stable manifold of the system is defined by

$$
X(t)=a V e^{\lambda_{1} t}
$$

where $V=\left[\begin{array}{lll}v_{1} & v_{2} & v_{3}\end{array}\right]^{T}$ is the eigenvector corresponding to the negative eigenvalue. Since capital is predetermined, one can write in level form $k(t)-k=(k(0)-k) e^{\lambda_{1} t}$. In difference form, the equations for the stable saddlepaths are

$$
\begin{aligned}
\mathrm{q} & =\frac{v_{2}}{v_{1}} \mathrm{k}=\frac{\lambda_{1}}{\psi_{1}} \mathrm{k}, \\
\mathrm{q}^{\pi} & =\frac{v_{3}}{v_{1}} \mathrm{k}=\frac{\psi_{3}+\psi_{4} \frac{\lambda_{1}}{\psi_{1}}}{\lambda_{1}-(r-g)} \mathrm{k} .
\end{aligned}
$$

From the assumptions, the first equation is negative sloping in $(k, q)$ space (the stable arm in the standard $q$-theory of investment set-up, amended for the presence of the inefficiency wedge $\mu$ ), but the sign of the second slope is ambiguous. One can nevertheless observe that average and marginal $q$ will behave differently for any given deviation of capital from its balanced growth path. 


\section{Calibration}

\subsection{The equity premium}

One of the driving variables in this model is the return on assets required by investors to smooth their consumption profile. In a stochastic setting, the two assets, bonds and equity, generate different returns as a reflection of their inherent riskiness. A vast body of literature flowed from analysing this premium of equity returns over the risk-free rate, and from attempting to reconcile it with observed consumption profiles, both across dates and states (see for example, Kocherlakota (1996), and Cochrane (1997)). This is of prime importance, in that a drop in the required return on assets, posited by a number of authors, is the key effect that justifies the run-up in equity values in the dividend discount model. However, in this framework, there is no uncertainty; both assets - stocks and bonds - earn the same return. Since the asset I am interested in tracking is equity, I will calibrate $r$ accordingly. From the continuous time-perfect foresight Euler equation (1), the required return depends on the growth rate of technology, on the coefficient of risk aversion and on the time preference rate (or equivalently the discount factor). Here, for a given growth rate and aversion to risk, I will follow Heaton and Lucas (1999) and model a drop in this return by postulating that the discount factor has fallen, i.e. that people are more long-sighted. In other words, observed values of $\gamma, \rho, r$ and $g$ are incompatible with the theoretical Euler equation. 'Something has to give' among the three parameters $\gamma, \rho$, and $g$ to justify the prevailing return $r$. In this paper, I take it to be $\rho$.

\subsection{Choice of calibration parameters}

The calibration will use the following parameters. Importantly these parameters reflect annual data.

\begin{tabular}{|l|l|l|l|l|l|}
\hline$\gamma=2$ & $\alpha=0.28$ & $\delta=0.06$ & $\chi=15$ & $g=0.015$ & $\rho=0.05$ \\
\hline
\end{tabular}

Some comments are in order about these choices. First, I take as fundamental benchmarks the two facts that the average log-real returns on US stocks over the 1947-1998 period is approximately $8 \%$ (8.1\% in Campbell (2001)), and the average capital-output ratio is 2 . From the equilibrium conditions derived above, and assuming that, on average, the pure 
profit share is zero, the choices of $\alpha$ and the depreciation rate $\delta$ are compatible with these long-run values. Second, the adjustment-cost parameter is the average value of the range chosen by Kiley (2000) for his calibrations, and is consistent with estimates in Cummins, Hassett and Oliner (1999). Third, I assume a growth rate of 1.5\%. Combined with the other parameters, this choice implies a long-run investment-output ratio of $15 \%, 1.5$ percentage points above the average over the sample period depicted in figure 2. Fourth, I assume a utility function more 'curved' than the standard logarithmic case. Sensitivity of results to these choices of risk aversion and growth is postponed to a later section. Nevertheless, as the previous subsection pointed out, the time preference rate $\rho$ is now tied down for model consistency by the other parameters to a value of 0.05 . Following Kiley, the initial steadystate is perturbed - in a deterministic sense - by assuming that the required rate of return drops to $4 \%$. This implies that $\rho$ drops to 0.01 .

Since the point of the calibration will be to compare the dynamics of the economy under both the PC-CRS and IC-IRS paradigms and under the potential presence of monopoly rents, the pure profit share $\pi$ and the value-added markup $\mu$ (or equivalently $\eta$ ) will take on several values. As was mentioned previously, the empirical literature on returns to scale and markups has been thriving in the past few years, but with great disparity of magnitudes involved (see Farmer (1999, p.172) for a more detailed presentation of the debate). Returns to scale seem to range from 1.03 at the low end (Basu and Fernald, 1997) —or even decreasing (Altug and Filiztekin, 2001) - to 1.4 at the high end (Rotemberg and Woodford, 1995). The calibration will cover this range for short-run and long-run analysis. It will be convenient to take the value of the latter set of authors as the upper bound of the range for purposes of comparison with existing literature. These authors assume $s_{m}=0.5$, observing that valueadded in manufacturing is only about half of gross output in manufacturing. By ruling out pure profits, their assumption that $\eta=\mu=1.4$ implies from equation (12) that the markup is $\frac{1}{\theta}=1.17$, which they view as a conservative measure.

An apology is in order, as the number of parameters of interest and related calibrations generates an even larger number of figures necessary to illustrate the point of this paper. For the purpose of form, these figures would inconveniently clutter the flow of text. Therefore, instead of being presented in line with the analysis, they are all displayed in this paper's 
appendix. The table on page 36 is produced to help keep track of them.

The calibrations involve several dimensions. The first ten figures analyse the effect of "shocks" (required return and markup) on variables in the presence of a permanent monopoly franchise. The remaining ten analyse the same parameter displacements when entry erodes this franchise. These shocks are taken individually and combined, the point of the exercise being to see how far plausibility of markups, scale, return and entry needs to be stretched to justify the high observed level of average $q$. To make the exercises comparable, the required return shock is modelled as a drop of $r$ from 0.08 to 0.04 , and the markup shock is such that the pure profit share is $3 \%$ (i.e. $\frac{\mu}{\eta}=1.03$ ) unless otherwise stated. This is the value Farmer (1999) uses for similar illustrative purposes.

\subsection{Implications for valuation and fundamentals of a drop in the required rate of return}

Figure 3 on page 37 depicts the benchmark calibration, run under perfect competition and constant returns to scale. The shadow price of capital, the stock market value of firms and the investment-output ratio jump on impact as expected, and in the long-run, $v^{*}=k^{*}$. Kiley's (2000) conclusions can be reproduced here: the investment-output ratio increases by more, and the stock market by less, than is warranted in the data (see figures 1 and 2), for the given hypothesis of a drop in the required rate of return.

Figure 4 shows the same impulse response functions ${ }^{7}$, but for a given small positive profit share, expected to be sustainable indefinitely. The effect of a drop in the required return is to magnify substantially the response of average $q$, and accordingly the stock market value of firms, which converges to a level above that of the new long-run value of capital (see equation (23)). ${ }^{8}$ Hence the presence of sustainable monopoly profits helps the model reproduce magnitudes of average $q$ observed in the latter part of the 1990s. The pricedividend ratio also jumps and converges to a much higher long-run value than under the

\footnotetext{
${ }^{7}$ Note that "impulse response" is somewhat of a misnomer, since it refers to the stochastic nature of the system under study. Here, the system is deterministic. Thus, the impulse-responses are in fact transitional paths from one deterministic equilibrium to another.

${ }^{8}$ The full lines track the fundamentals $(q$ and $k$ ), while the dashed lines track the valuations (average $q$ and $v$ ). The dotted lines indicate the pre-jump values of the valuation variables, which are not necessarily the same as those of the fundamentals.
} 
PC-CRS case. Notice however that the level of capital is slightly lower than in the perfectly competitive set-up, since the presence of the inefficiency wedge reduces its steady-state value. On the other hand, as was commented above, the investment-output ratio also jumps, and the presence of a positive profit share does not seem to dampen the jump in any substantial way.

The following five figures analyse the sensitivity of these impulse-response functions along the dimensions of profit and scale. As figures 5 and 6 show on page 38, marginal $q$ becomes less responsive on impact to a drop in the required return for both higher returns to scale and profit rates. This occurs because at higher scale, less capital is needed in the future to produce consumption compatible with the lower returns required by agents. On the other hand, average $q$ becomes relatively more responsive on impact with higher profit rates. This clearly arises because of the increased discounting effect $(r-g)$ on the monopoly franchise. The discrepancy between the percentage jump of average $q$ (figure 7) and its absolute value on impact (figure 6) comes about because average $q$ starts before the jump at a value above 1 , precisely because of the existence of the monopoly franchise (see the dotted lines in figure 4). Figure 9 shows by how much equity increases in the long run for given profit rates (the increase of the capital stock in the long-run is observed on the graph at the zero-profit share increment).

The main result of this first exercise is that it is quite easy to reproduce observed valuation levels, once one accounts for the capitalized value of future monopoly profits, which could be small at any point in time. However, figure 8 shows that the sensitivity of the investment-output ratio to the required return actually increases as a function of both profits rates and scale. That is, by explaining the valuation conundrum, the model compounds the fundamentals conundrum.

\subsection{Markup shocks}

Introducing market power enables us to analyse another possible source of disturbance to the economy, namely markup shocks. Rotemberg and Woodford (1999) survey several theories of markup determination, but in this model, the markup is simply assumed to be exogenous. Figure 10 plots the impulse responses of the same variables for a change in the prevailing 
profit share (given a constant discount rate $r^{*}$ ). A positive markup shock drives a greater wedge between average and marginal $\mathrm{q}$, as the two variables jump in opposite directions. The price-dividend ratio also increases. But the disturbance implies a drop in the investmentoutput ratio, as well as in the capital stock, while increasing the stock market value of firms. This comes about because a higher markup causes greater inefficiency (a greater gap between marginal product and factor price which leads to suboptimal supply of the factor) and increases the profit share. Notice however that magnitudes involved are very small, except for the value of equity, which for this particular calibration increases by around $18 \%$.

The two calibration exercises illustrate how allowing for monopoly rents can change the scale of the response of the system to a shock to the rate of return, and can introduce a different and potentially important source of shock to the system, precisely via these rents. The calibrations show that quantitatively, both the rate of return and markup shocks work in the same direction on impact for average $q$, and hence for the stock market $v$, but work in the opposite direction for marginal $q$ and the investment-output ratio. An immediate follow-up would be to analyse whether a combination of shocks could explain high valuation and low investment response. This exercise is performed in the next section, which assumes more realistically that monopoly franchises are temporary. The reason is that, individually, the rate of return and markup shocks can be expected to have less of an effect on the system when franchises are temporary than when they are permanent. It therefore seems logical to see whether their combined effect can compensate the shortfall of their individual effects.

\section{Entry condition}

\subsection{Dynamics of fixed costs}

To maintain permanent rents, the previous section assumed that returns to scale were timeinvariant. This required that

$$
\Phi(t)=\frac{\eta-1}{\eta} y(t)
$$

namely that fixed costs are a fixed proportion of output, or equivalently that the ratio of fixed to variable costs is constant. Clearly, this defeats the definition of costs as 'fixed', but this is the bane of attempting to model permanent rents in a model of monopolistic competition. The 
previous calibration postulated the existence of a positive long-run profit share, which came about because of the long-run gap between markups and returns to scale. This assumption may be too strong, although models of imperfect competition exist where monopoly franchises are permanent. ${ }^{9}$ Indeed, the revival of the 'creative destruction' approach to growth theory relies precisely on the idea that monopoly franchises are the necessary incentive to promote growth.

Although the literature has traditionally assumed that there were no long-run profits to be made - because free entry would wipe these away - there seems to be little reason not to expect some short run pure profits. In this section, I amend the previous model by adding an entry-and-exit condition that links markups and returns to scale so that profits are zero in the long-run,

$$
\dot{\Phi}=-\phi\left(\Phi-\Phi^{*}\right)
$$

with the steady-state level of fixed costs per capita defined by $\Phi^{*}=\frac{\mu-1}{\mu} y^{*}$.

This autoregressive process follows Zellner (2000). It captures very crudely the notion that short run aggregate pure profits are possible for deviations of markups with respect to the long-run, but they are eroded by an increase in returns to scale, which arises from the increase in the number of firms entering the market and facing fixed costs of production. The obvious objection to such an equation is its lack of micro-underpinning: there is no sense of optimisation behind it, as firms enter and exit sectors in a mechanistic fashion. However, I follow other authors by introducing such a basic behavioral equation (see again Rotemberg and Woodford (1995) and again, for empirical work, Zellner (2000) and references therein), which still captures some interesting features from the existence of short-run monopoly profits. Given that $\Phi^{*}$ depends on both productivity growth and markups, I can proceed with the same exercise as before with this extra dynamic equation. Since there are no sustained profits, $q^{\pi *}=0$, ie average $q$ equals marginal $q$ in the long-run. The equations that need modifying

\footnotetext{
${ }^{9}$ In fact, there are a number of models which imply sustained monopoly profits, even in the presence of entry. For a series of references, see Eaton and Lipsey (1997), and their Chapter 6 in particular.
} 
are (27) and (30), which now become

$$
\begin{aligned}
f_{k} \mathrm{k} & =\mathrm{c}+\mathrm{i}-\Phi \\
\dot{\mathrm{q}}^{\pi} & =\left(r^{*}-g\right) \mathrm{q}^{\pi}+\frac{\mu-1}{\mu(1-\alpha)} f^{\prime \prime}\left(k^{*}\right) \mathrm{k}+\frac{1}{k^{*}} \Phi
\end{aligned}
$$

with the dynamics of fixed costs

$$
\dot{\Phi}=-\phi \Phi .
$$

This results in the following system:

$$
\dot{X}=A_{2} X,
$$

where

$$
\begin{aligned}
X^{T}= & {\left[\begin{array}{cccc}
\Phi & \mathrm{k} & \mathrm{q} & \mathrm{q}^{\pi}
\end{array}\right], } \\
A_{2}= & {\left[\begin{array}{cccc}
-\phi & 0 & 0 & 0 \\
0 & 0 & \frac{\mu k^{*}}{\chi} & 0 \\
\frac{\phi \gamma}{c^{*}(1+\xi)} & -\frac{f^{\prime \prime}\left(k^{*}\right)}{\mu(1+\xi)} & r^{*}-g+\psi_{5} & 0 \\
k^{*-1} & \frac{(\mu-1) f^{\prime \prime}\left(k^{*}\right)}{\mu(1-\alpha)} & 0 & r^{*}-g
\end{array}\right], } \\
\psi_{5}= & \frac{\xi}{1+\xi}(\mu-1)\left(r^{*}+\delta\right),
\end{aligned}
$$

and the other parameters are defined as before. Note again that the matrix is lower blocktriangular, so its eigenvalues are (minus) the speed of entry $-\phi$, the discounting term $r^{*}-g$, and the two eigenvalues of the Abel-Blanchard sub-matrix (the middle block in $A_{2}$, in (k, $\mathrm{q}$ ) space). The determinant is non-zero and there are two negative eigenvalues $\left(\lambda_{1}\right.$ and $\left.-\phi\right)$ corresponding to the two predetermined variables ( $\Phi$ and $k$ ); therefore, the system is stable in Blanchard and Kahn's (1980) sense. Again, shocks to the system will have a different impact on average and marginal $q$. 


\subsection{Calibrations}

Figure 11 on page 41 shows the time paths of the variables after a drop in $r$ in the presence of returns to scale of 1.4 (the Rotemberg-Woodford value - the upper bound on markup data) and a speed of adjustment arbitrarily set at 0.3. Again, average $q$ is more responsive than marginal $q$, but less so than in the presence of a permanent monopoly franchise. The investment-output ratio jumps by the same amount as in the benchmark case. A noteworthy feature is that the price-dividend ratio, equity and the investment-output ratio jump to values close to their steady-states, and follow what seem like cyclical processes, which are simply the reflection of the interaction of two negative eigenvalues determining the dynamics of the system. Figure 12 plots the initial jump of average $q$, and by extension of the stock market (since capital is predetermined), after a drop in the required return, for different values of scale and speed of adjustment. The noticeable feature is the upward 'flap' at higher scale and lower speed, values for which the stock market value can easily double. ${ }^{10}$. This cusp is reversed for the sensitivity of the responsiveness of the $i / y$ ratio to the drop in $r$, as figure 13 shows. For low values of the speed of entry, this ratio increases by substantially less than otherwise. It therefore appears that the empirical value of the rate of entry is of prime importance if this crude model is to replicate the basic features of the data by appealing solely to a drop in the equity premium.

Figure 14 plots the time paths of the variables in response to a sudden increase in the markup, for a given required rate $r$. For this particular calibration, the markup is assumed to increase permanently by $10 \%$, with fixed costs adjusting to eliminate the excess profits. There are two noteworthy results. First, average $q$ is a cyclical amplification of marginal $q$. This implies that the stock market overshoots its long-run value, as it must converge to a lower capital stock induced by the higher inefficiency wedge. Second, as opposed to the calibration with permanent monopoly franchises, the increase in the markup actually increases the investment-output ratio, and does so by a significant amount. Figure 15 shows exactly how this ratio reacts to a markup increase from the benchmark of perfect competition.

Figure 16 plots the response to a joint drop in $r$ to 0.04 , and a $10 \%$ increase in $\mu$. As

\footnotetext{
${ }^{10}$ This cusp, interestingly, appears at speeds of entry that Rotemberg and Woodford use for their calibration exercise on employment (1995), which suggests that their results obtain only under the restrictive assumption of very slow erosion of profits.
} 
can be noticed, the dynamics are qualitatively quite different from those obtained in the presence of a permanent monopoly franchise. Figure 17 shows the impact on average $q$ (and on market value) of a joint shock to $r$ and $\mu$, from an initial steady-state of constant returns and marginal pricing, for a given speed of entry. Figure 18 shows the same impact for the given shock of $r=0.04$, for various values of the markup shock and the speed of entry. Again, the speed of entry plays a crucial role, and the combined effect of lower required returns and markup shock can reproduce the observed values of average $q$ with the added restriction of no long-run profits. However, again, this is possible either with a very slow rate of entry, or substantially large markup changes, much larger than in the model of section 3 , since they must compensate for the erosion of the value of the monopoly franchise which was assumed permanent therein. Figure 19 shows that the fundamentals conundrum is still present, as only a very slow speed of entry and a high markup change can dampen the effect of $r$ on $i / y$.

Finally, figure 20 shows that the long-run effect of the presence of increasing returns to scale (or equivalently market power) is actually to decrease the long-run value of capital (and by extension, the stock market) for a given required rate of return on assets.

\section{$5 \quad$ Discussion and Extensions}

\subsection{Intertemporal substitutability and the growth rate}

Sensitivity analysis can be done on a number of parameters in this model, but a full quantitative exercise would cause the paper to lose its focus, which is specifically the sensitivity of asset prices to market power and scale. For the sake of completeness, however, I can qualitatively assess the impact of the choices of prevailing risk aversion $\gamma$ and growth $g$ on the calibration results of 3 . Looking again at the steady-state values of average $q$ and the investment-output ratio in equations (24) and (25), these depend on the ratio $\kappa=\frac{r+\delta}{r-g}$. Recall that the calibrations were done on the assumption that $\rho$ changes in a way that is compatible with a postulated drop in $r$ and a prevailing growth rate. Note that

$$
\begin{aligned}
\frac{d \kappa}{d \rho} & =-\frac{g+\delta}{\left(r^{*}-g\right)^{2}}<0, \\
\frac{d \kappa}{d g} & =\frac{\rho-(\gamma-1) \delta}{\left(r^{*}-g\right)^{2}} \lesseqgtr 0 .
\end{aligned}
$$


The effect of the time preference rate on $\kappa$-and hence of $r$, holding $g$ constant, on average $q$ and the $i / y$ ratio - is unambiguous. But the effect of $g$ on $\kappa$ depends on the degree of risk aversion. Growth has two competing effects. It increases the output-capital ratio (since output is produced with more effective labor) and therefore the value of the monopoly rents. But it also increases the required return which discounts these future higher rents. Greater risk aversion requires a higher return to entice consumers to substitute consumption intertemporally. This second effect is more likely to dominate the first, precisely when $\rho<(\gamma-1) \delta$. The implication is that an increase in $g$ can have an adverse effect both on long-run valuation and investment-output ratios.

In light of this observation, the choice of $\gamma=2$ and $g=1.5 \%$ is not innocuous. To see this, consider the cross-derivative:

$$
\frac{d^{2} \kappa}{d \rho d g}=-\frac{1}{\left(r^{*}-g\right)^{3}}[\rho-(\gamma-1)(g+2 \delta)]>0 .
$$

The parameters impose a positive cross-derivative which, combined with $\frac{d \kappa}{d \rho}<0$, implies that the higher the prevailing growth rate the more dampened the long-run boost to the two ratios of interest from a drop in $r$. The choice of log-utility, however, reverses the sign of this cross-derivative, implying that a higher prevailing growth rate enhances the impact of this drop.

This sensitivity analysis is not tractable for the short-run impact of shocks to the system. An alternative calibration was run with logarithmic utility and a zero growth rate, under the same conditions of a drop of $r$ from $8 \%$ to $4 \%$. The implications are that valuation ratios are less responsive to this drop than in the original calibration, while fundamentals are more responsive. Hence the original selection of parameters seems to fit better with observations ${ }^{11}$.

\subsection{Time scale and the significance of $\phi$}

As was emphasized at the beginning of the quantitative section, the model is calibrated according to annual data. This means that the time scale in the impulse response functions is measured in years. Clearly, the reversion to equilibrium is done on a scale beyond business-

\footnotetext{
${ }^{11}$ These alternative results are available upon request.
} 
cycle analysis: it takes about 15 years for $q$ to decay halfway back to 1 in the PC-CRS case (in figure 3). Under this paradigm, the model does not capture business-cycle features of asset valuation, but rather the underlying secular trends. However, the markup and the speed of entry affect the system's eigenvalues that determine mean-reversion, and the latter is substantially accelerated - about 5 to 7 years of half-lives - for most figures where these parameters differ from the benchmark of PC-CRS. This suggests that estimating the markup and the speed of entry is of prime importance.

Consider $\phi$, which measures the speed of catch-up of fixed costs $\Phi$ to their new long-run equilibrium. To make sense of it, consider the choice made in this paper of calibrating it to 0.3. This implies that it takes $T=\frac{\ln 2}{\phi}=2.3$ years for fixed costs to cover half the distance to the new steady-state. For comparison purposes, the annual value used by Rotemberg and Woodford (1995), $\phi=0.08$, implies a half-life of $T=8.6$ years, which seems inordinately long. Yet, looking at figure 12, only a very small value of $\phi$ can help the model reproduce the magnitude of observed valuation ratios. Unfortunately, the choice of $\phi$ is completely ad hoc. There is no data available to my knowledge that would enable me to infer a 'sensible' value. The natural instinct is to calibrate on the basis of the expected number of years it would take to erase half of existing pure profits. But this calibration is not a simple exercise, since profits depend both on $\Phi$ and on $y$-hence on the two negative eigenvalues of the system-making the relationship between $T$ and $\phi$ non-monotonic. Exploring the significance and the scale of $\phi$ is an obvious direction for extending the quantitative understanding of the effect of pure profits on valuation.

\subsection{Habits}

As is well-known from the literature (see Kocherlakota (1996) for example), general equilibrium models have long failed to account jointly for the equity-premium and risk-free rate puzzles. One partial way out of this conundrum involves generalising the representative consumer's utility function. More specifically, a number of authors have explored the implications of habit formation for asset pricing. Some modelling issues arise about functional forms and existence of consumption externalities, namely choosing between additive and multiplicative, and internal versus external habits, as well as the speed with which habits adapt to current 
consumption levels. These issues are discussed at length in Campbell, Lo and Mackinlay (1997, Chap. 7).

This paper has bypassed the equity premium puzzle in two ways: first, simply by adopting a non-stochastic framework, and second, by adopting the assumption of time-separable utility. Relaxing the latter assumption along the lines described in the previous paragraph may still enable the paper's model to replicate more closely observed data. In fact, this paper was written with the first version of Kiley's (2000) working paper in mind, which dealt with a standard time-separable utility-based asset pricing model. In the latest version, Kiley incorporates habit formation in his model. He still retains his original conclusion, which is that general equilibrium modelling with production refutes the asset pricing consequences of a drop in the equity premium in the dividend discount model. Habit formation, however, does affect the path of investment, since it is defined as non-consumed output.

From this paper's perspective, however, the behavior of marginal $q$ and the rate of return under habit formation as described by Kiley would still only be half of the story. Recall from equation (23) that average $q$ and marginal $q$ differ by a term that one can represent as $\frac{M P}{r-g}$, where $M P$ stands for 'monopoly profits'. Adopting habit formation may be a cleaner way of modelling the discounting effect in this wedge (the denominator), but it does not alter the pure profit share $\mu \eta^{-1}$, which underpins the term $M P$. In other words, habit formation affects the representative agent's choice of a consumption profile, but it clearly does not affect the market structure in which production is undertaken. The crux of this paper is that the latter matters.

\subsection{Labor-leisure choice}

In this model, I have made the strong assumption that labor supply is fixed. This is an easy restriction to relax, but I refrain from doing so purely for simplification. This is another extension worth exploring, although some of the conclusions from it may be tentatively sketched out. First, as observed from the first structural matrix $A$ that governs the system, it is block lower-triangular and its determinant is negative, which implies that all three roots are real. Hence there is no cyclical behavior in any of the variables tracked by the model, regardless of the prevailing market power and returns to scale. However, the inclusion of 
labor supply decisions in the model, through the related optimality condition on consumption and leisure, causes these parameters to influence the determinant and eigenvalues of the new matrix. As some authors suggest (Farmer and Guo (1994), Benhabib and Farmer (1994)), for certain values of the elasticity of labor supply and returns to scale, the system may be driven by complex roots and endogenously persistent behavior, leading to more interesting cyclical dynamics that, according to these authors, seem to fit US data much better than under the PC-CRS paradigm. Later research has cast doubt over whether the required magnitude of the parameters is actually observed to justify cyclical behavior (see Basu and Fernald (1997), Rotemberg and Woodford (1995)), but it may be worth investigating this further in this framework, where another source of friction in input markets is introduced in the form of capital installation costs.

Second, because of the gap between marginal products and factor prices, a technology shock has a stronger effect on output than in the PC-CRS case, through the increase in the effective units of labor that a firm hires. However, it has a weaker effect on employment, through a stronger wealth effect in the labor supply decision that come about from the existence of the markup (see again Rotemberg and Woodford (1995)). Given the substitutability of labor and capital, the substitution of current work for future leisure may dampen the effect of a change in technology on capital accumulation. The size of this new response is also worth exploring. A companion paper (citation to come) explicitly accounts for the effect of labor on asset prices.

\subsection{Estimating markup changes}

Consider now the markup $\mu$. As the last calibration exercises showed, it is possible to reconcile magnitudes of valuation ratios with a business-cycle model if one accepts the possibility of large swings in the prevailing markup and the pure profit share. In this paper, these were assumed. However, data on both variables can be constructed from the optimality conditions of the model. Consider equation (9). Multiplying by the labor-output ratio and using the definition of returns to scale yields

$$
\frac{w n}{y}=\mu^{-1} \frac{f_{n}(k, A n, i)}{f} \frac{f}{y}=\frac{\eta}{\mu} \alpha
$$


Hence, by assuming for example that constant returns to scale prevail and that the production function is Cobb-Douglas, the markup moves inversely with the labor share. Rotemberg and Woodford (1999) proceed in this direction in order to build a markup series and analyse the effects markups have on output and employment. The extension to this model of asset pricing is quite straightforward, once one recognizes that a forward-looking rational firm will optimize profits along each of its input margins. That is, a markup series can be constructed from the first order condition on labor to test the one on capital and its 'Hayashi' extension, equation (14). This is the focus of a companion paper.

\section{Conclusion}

The driving idea of this paper was to investigate whether the analysis of stock prices in a general equilibrium model with production could be amended sufficiently with the introduction of market power to account for the behavior of the stock market in the late 1990s. The attraction of the dividend discount model stems from the hyperbolic effects of changes in discount factors on an exogenous infinite stream of income. From a general equilibrium perspective, however, this hyperbolic effect is dampened, precisely because this stream dividends- is endogenously determined by the discount rate. Nevertheless, the $q$-theory of investment also values equity as a discounted stream, but of contributions of the capital stock to future output (directly through marginal products and indirectly through reduced capital installation costs). This paper recognizes that this discounted stream should include the future value of monopoly rents. This suggests that the hyperbolic effect of discounting applies to an extra term which could be sizeable enough to compensate the shortcomings of the $q$-theory to account for observed data.

Indeed, under the perfect competition-constant returns to scale paradigm, as Kiley (2000) pointed out, only half of observed stock valuations could be explained by a potential permanent shift in fundamentals. Introducing market power goes a lot further towards mimicking observed short-run movements in valuation. As was seen in sections 3 and 4 , the combination of a drop in required returns and an increase in prevailing pricing power can push average $q$ to observed levels. Moreover, changes in markups could also qualitatively account for the puzzling dissociation of investment and valuation time-series observed from the mid-1970s to 
the mid-1980s.

However, the long-run properties of the model do not bode well for future valuation, since $q$ is a mean-reverting process. In order to obtain an equity value permanently higher than the capital stock, the model must posit a permanent monopoly franchise, which is a serious departure from the Chamberlinian tradition. Adding an entry-and-exit condition captures short-run divergence between price variables, but the long-run implications of the model are necessarily similar to that of Kiley's: deviations should be eventually erased, and valuation should revert to a long-run level whose calibrated value is lower than currently observed data. Moreover, the amended model still requires too high an investment intensity in the economy compared to the data. Finally, introducing simple markup shocks creates the potential for more interesting dynamics, but the scale of these dynamics is small, and improbably large changes in market power are required to match the data.

The positive aspect of these results is that the introduction of market power in a general equilibrium model with production is straightforward, and highlights an obvious weakness in the standard $q$-theory of investment, namely the oversight of the value of monopoly franchises. It also highlights the need to integrate the empirical literature on imperfect competition, particularly that on the estimation of time-varying markups and returns to scale, to conduct more appropriate econometric analysis of investment and valuation behavior.

\section{References}

Abel, A. B. and Blanchard, O. J. (1983). An intertemporal model of saving and investment, Econometrica 51: 675-92.

Altug, S. and Filiztekin, A. (2001). Scale effects, time-varying markups and the cyclical behaviour of primal and dual productivity. University of York Working Paper.

Basu, S. and Fernald, J. (1995). Are apparent productive spillovers a figment of specification error?, Journal of Monetary Economics 36(1): 165-88.

Basu, S. and Fernald, J. (1997). Returns to scale in US production: Estimates and implications, Journal of Political Economy 105: 249-283. 
Baxter, M. and King, R. (1991). Productive externalities and business cycles. Discussion Paper 53. Institute for Empirical Macroeconomics. Federal Reserve Bank of Minneapolis.

Benhabib, J. and Farmer, R. E. (1994). Indeterminacy and increasing returns, Journal of Economic Theory 63: 19-46.

Blanchard, O. J. and Kahn, C. M. (1980). The solution of linear difference models under rational expectations, Econometrica 48(5): 1305-11.

Bond, S. R. and Cummins, J. G. (2000). The stock market and investment in the new economy: some tangible facts and intangible fictions, Brookings Paper on Economic Activity pp. 61-124.

Bond, S. R. and Cummins, J. G. (2001). Noisy share prices and the $q$ model of investment. Working Paper W122, Institute of Fiscal Studies, London.

Caballero, R. J. and Lyons, R. K. (1992). External effects in US procyclical productivity, Journal of Monetary Economics 29: 209-26.

Campbell, J. Y. (2001). Understanding risk and return. May 2001 Marshall Lectures, University of Cambridge, http://www.econ.cam.ac.uk/faculty/marshlec.

Campbell, J. Y., Lo, A. W. and Mackinlay, A. C. (1997). The Econometrics of Financial Markets, Princeton University Press, Princeton, NJ.

Cochrane, J. (1997). Where is the market going? uncertain facts and novel theories. Economic Perspectives, Federal Reserve Bank of Chicago.

Cummins, J., Hassett, K. and Oliner, S. (1999). Investment behavior, observable expectations and internal funds. Federal Reserve Board FEDS paper 1999-27.

Dixit, A. and Stiglitz, J. (1977). Monopolistic competition and optimum product diversity, American Economic Review pp. 297-308.

Domowitz, I. R., Hubbard, G. and Peterson, B. C. (1988). Market structure and cyclical fluctuations in us manufacturing, Review of Economic Statistics 70: 55-66. 
Eaton, B. C. and Lipsey, R. G. (1997). On the Foundations of Monopolistic Competition and Economic Geography - The Selected Essays of B. Curtis Eaton and Richard G. Lipsey, Edward Elgar, Cheltenham, UK.

Fagnart, J.-F., Licandro, O. and Portier, F. (1999). Firm heterogeneity, capacity utilization and the business cycle, Review of Economic Dynamics 2: 433-455.

Farmer, R. E. (1999). Macroeconomics of Self-Fulfilling Prophecies, MIT Press, Cambridge, Mass.

Farmer, R. E. and Guo, J. T. (1994). Real business cycles and the animal spirits hypothesis, Journal of Economic Theory 63: 42-73.

Hall, R. E. (1990). Invariance properties of Solow's productivity residual, in P. Diamond (ed.), Growth, Productivity, Unemployment, MIT Press, Cambridge, Mass., pp. 71-112.

Hayashi, F. (1982). Tobin's marginal $q$ and average $q$ : a neoclassical interpretation, Econometrica 50: 213-224.

Heaton, J. C. and Lucas, D. J. (1999). Stock prices and fundamentals, in B. Bernanke and J. Rotemberg (eds), 1999 NBER Macroeconomics Annual, Cambridge: MIT Press.

Kiley, M. T. (2000). Stock prices and fundamentals in a production economy. Finance and Economics Discussion Series 2000-05, Board of Governors of the Federal Reserve System.

Kocherlakota, N. R. (1996). The equity premium: It's still a puzzle, Journal of Economic Literature 34: 42-71.

Licandro, O. (1992). Investment dynamics and capacity utilization under monopolistic competition, Annales d'Economie et de Statistique 27: 91-113.

Prescott, E. C. (2002). Prosperity and depression - the Richard T. Ely lecture, American Economic Review 92(2): 1-15.

Robertson, D. and Wright, S. (2002a). What does $q$ predict? unpublished manuscript. 
Rotemberg, J. J. and Woodford, M. (1995). Dynamic general equilibrium models with imperfectly competitive product markets, in T. Cooley (ed.), Frontiers of Business Cycle Research, Princeton University Press, Princeton, NJ, pp. 243-293.

Rotemberg, J. J. and Woodford, M. (1999). The cyclical behaviour of prices and costs, in J. Taylor and M. Woodford (eds), Handbook of Macroeconomics, Vol. 1B, Elsevier, North-Holland, pp. 1051-1135.

Summers, L. H. (1981). Taxation and corporate investment: a $q$-theory approach, Brookings Papers on Economic Activity pp. 67-127.

Zellner, A. (2000). The Marshallian macroeconomic model. Professor Ryuzo Sato Research Conference Paper. 


\section{$7 \quad$ Appendix}

\begin{tabular}{|c|c|c|c|c|c|}
\hline 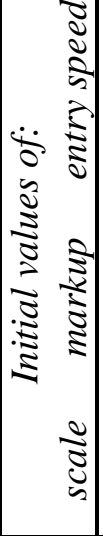 & 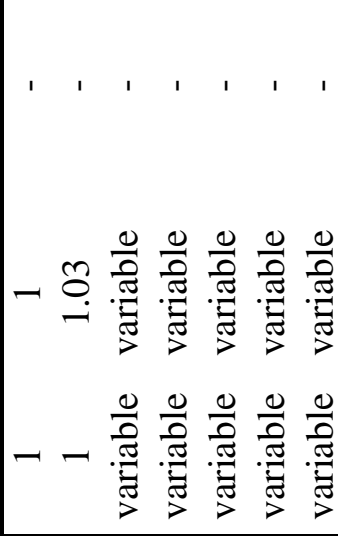 & - & 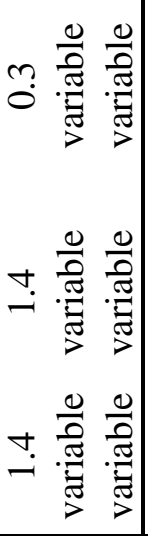 & ñ & 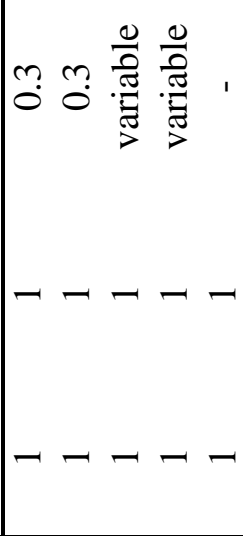 \\
\hline 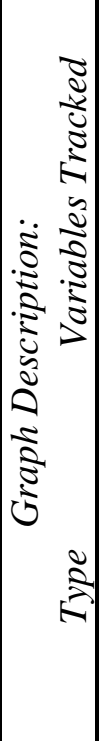 & 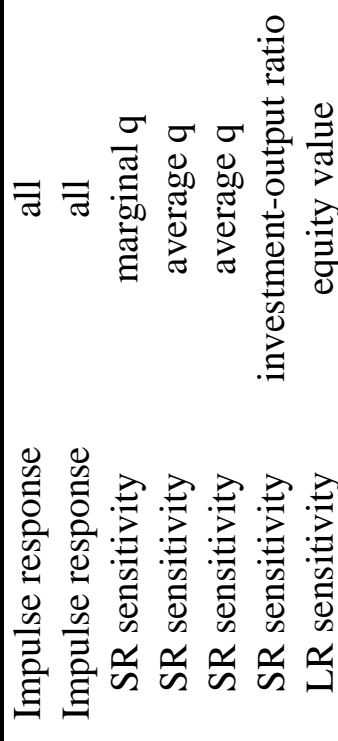 & 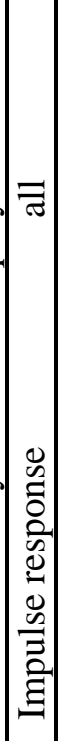 & 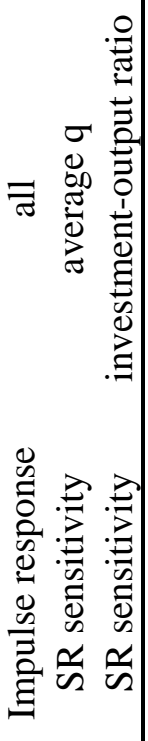 & 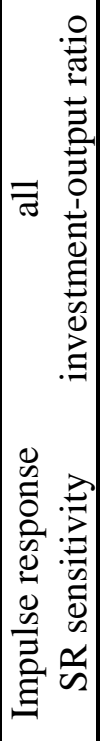 & 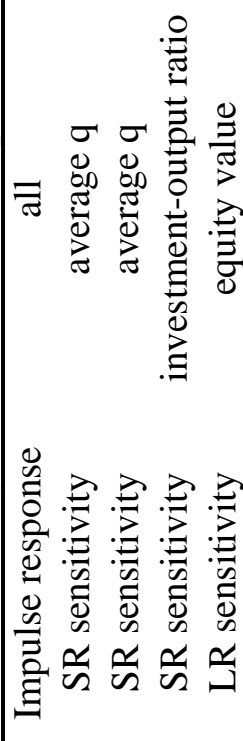 \\
\hline 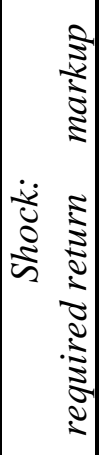 & $\mid \begin{array}{lllllll} & d & d & d & 0 & 0 & 0 \\
0 & 0 & 0 & 0 & 0 & 0 & 0 \\
0 & 0 & 0 & 0 & 0\end{array}$ & 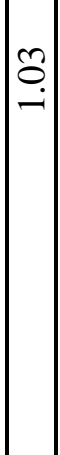 & $\begin{array}{lll}4 & + & 0 \\
0 & 0 & 0 \\
0 & 0\end{array}$ & $=\frac{\frac{0}{0}}{\stackrel{0}{\frac{\pi}{\pi}}}$ & 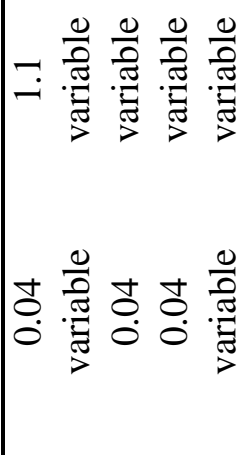 \\
\hline $\begin{array}{l}3 \\
0 \\
0\end{array}$ & $\operatorname{tin} 0 \wedge \infty a$ & 의 & $=\simeq \cong$ & $\pm \curvearrowleft$ &  \\
\hline
\end{tabular}



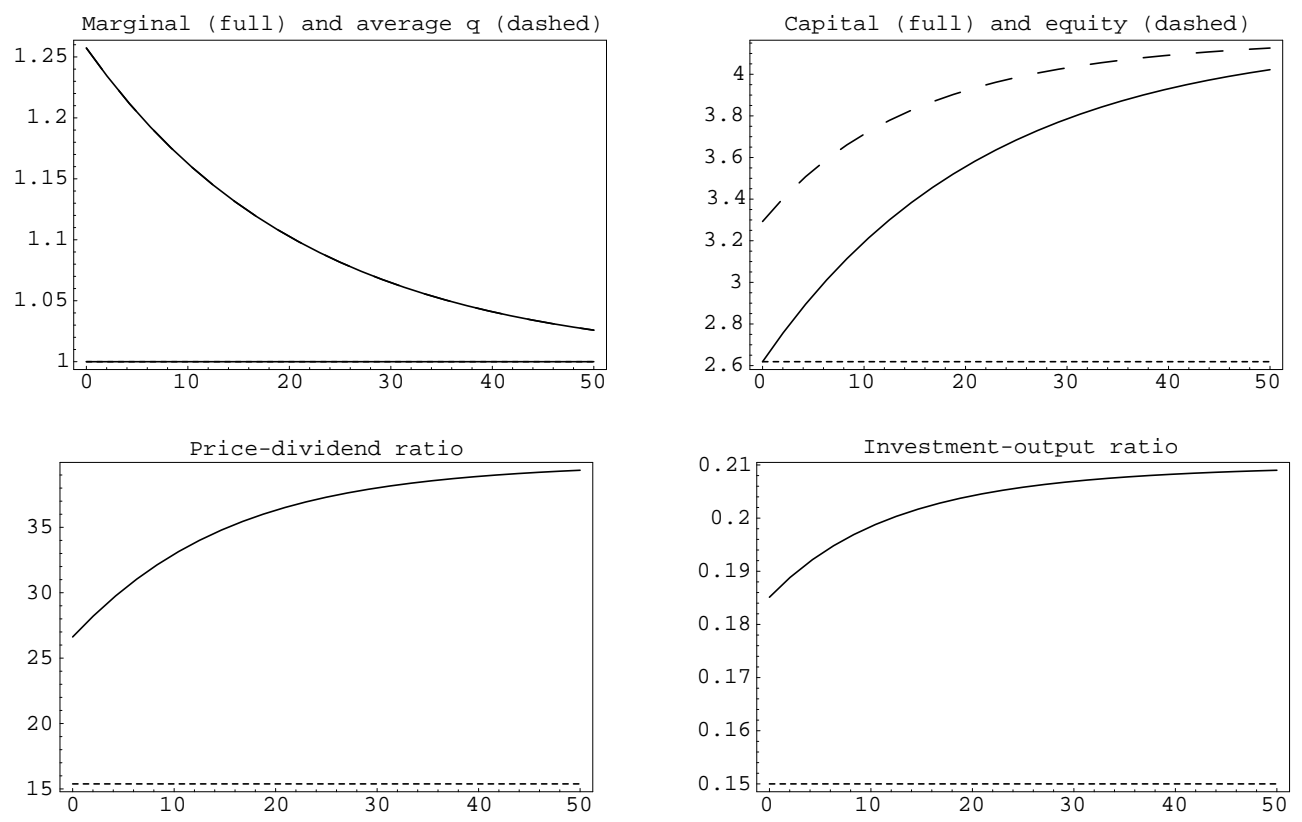

Figure 3: Impulse response - drop in required return to $r=4 \%$ with $\mu=\eta=1$
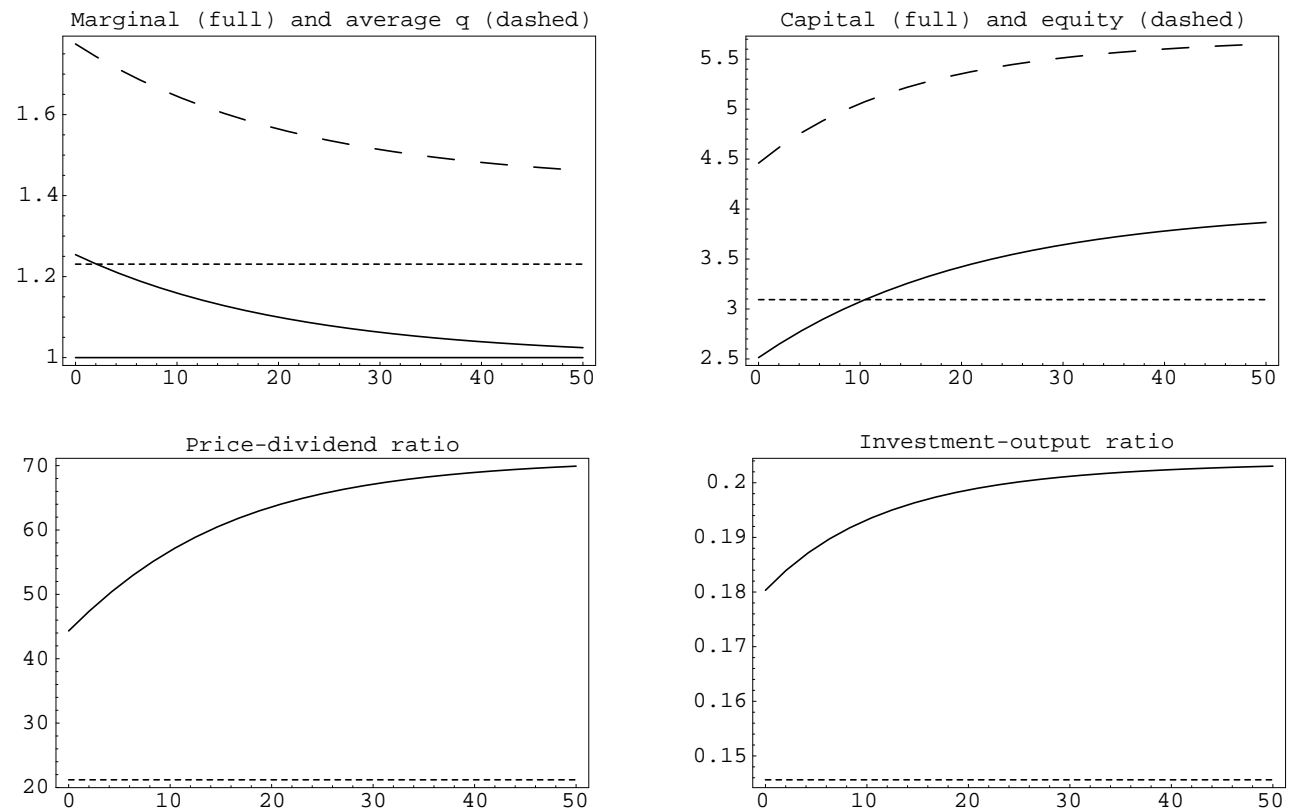

Figure 4: Impulse response - drop in required return to $r=4 \%$ with $3 \%$ permanent profit share $(\mu=1.03, \eta=1)$ 


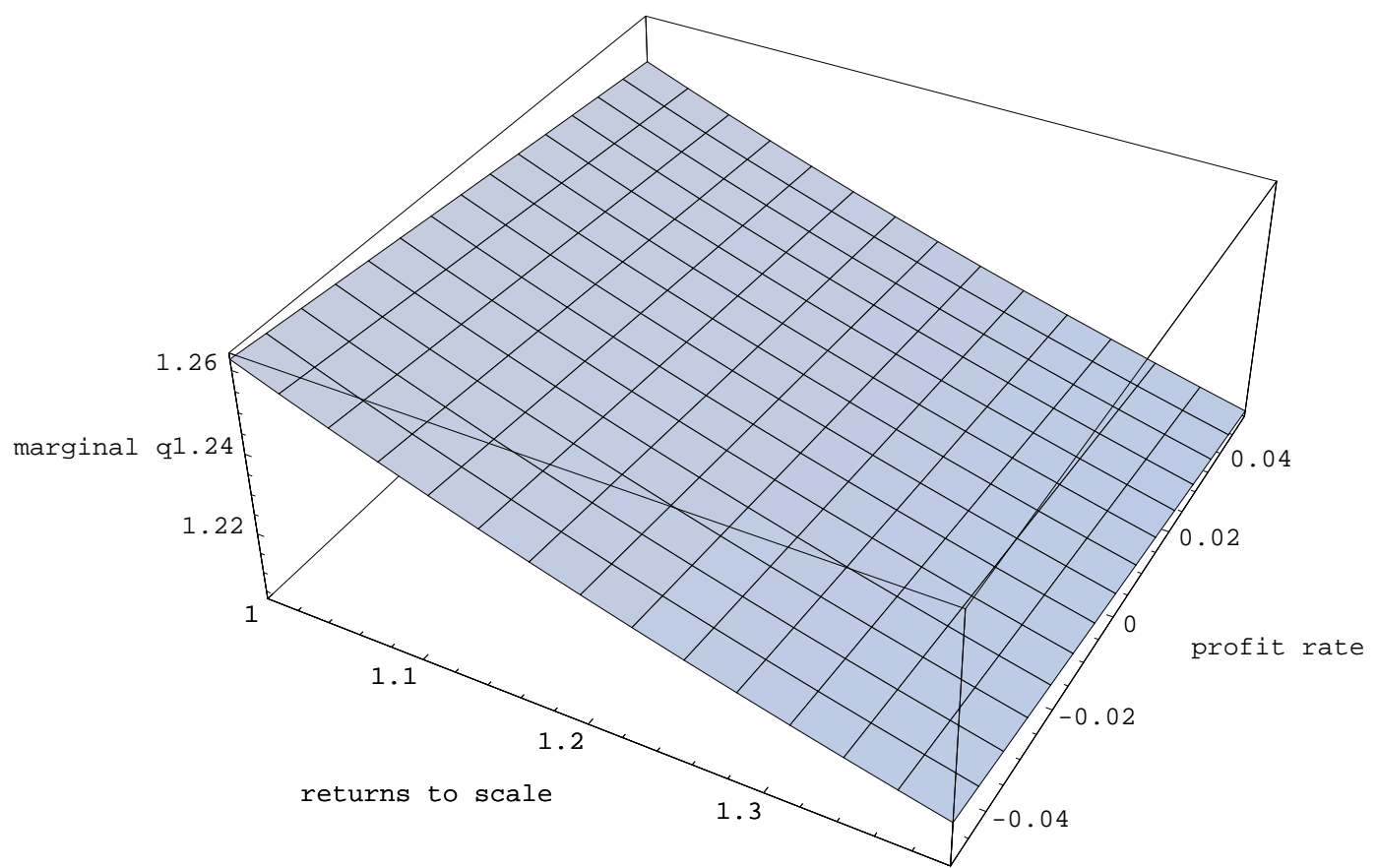

Figure 5: Marginal $q$ on impact as a function of scale and profit share

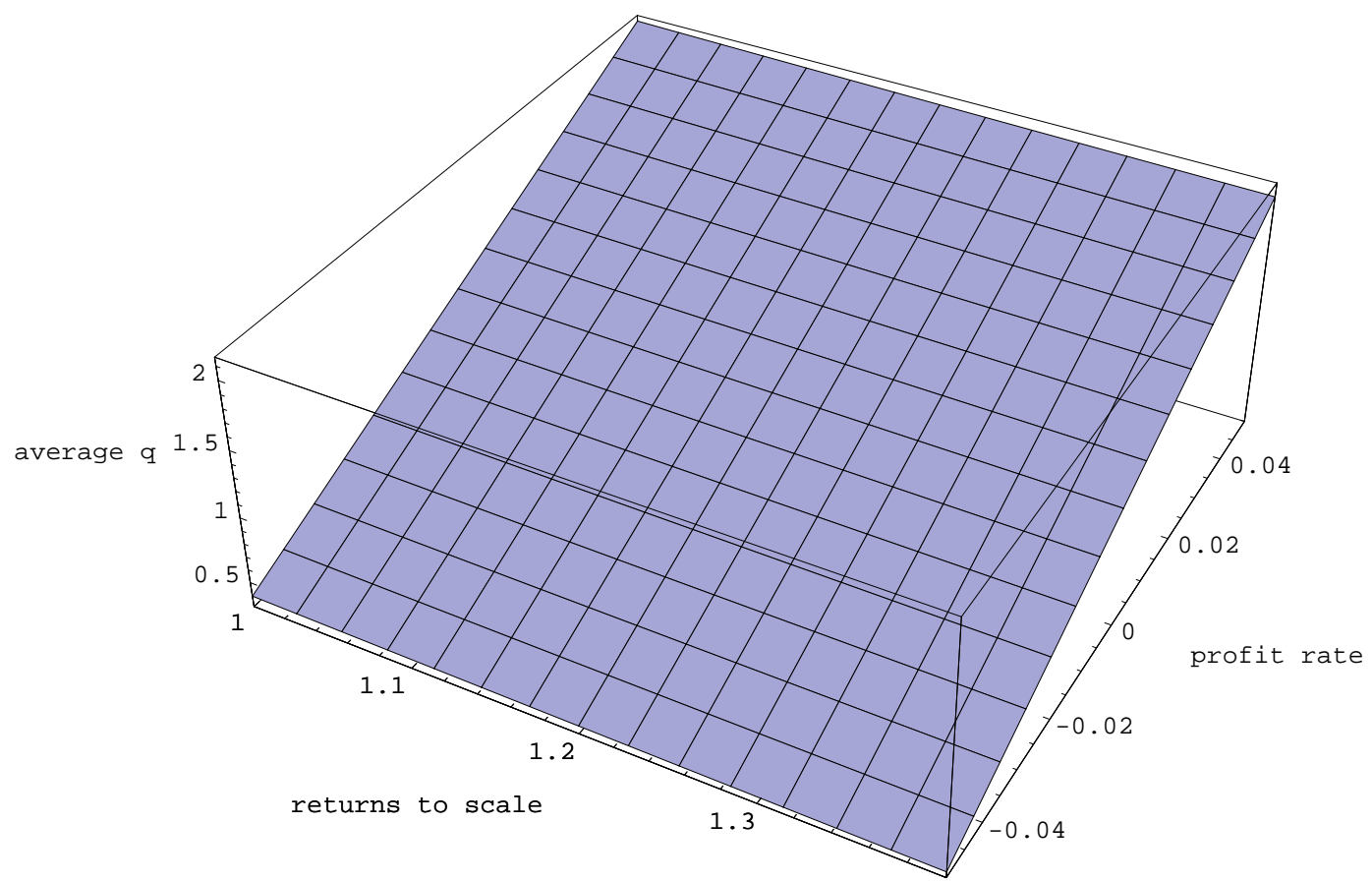

Figure 6: Average $q$ on impact as a function of scale and profit share 


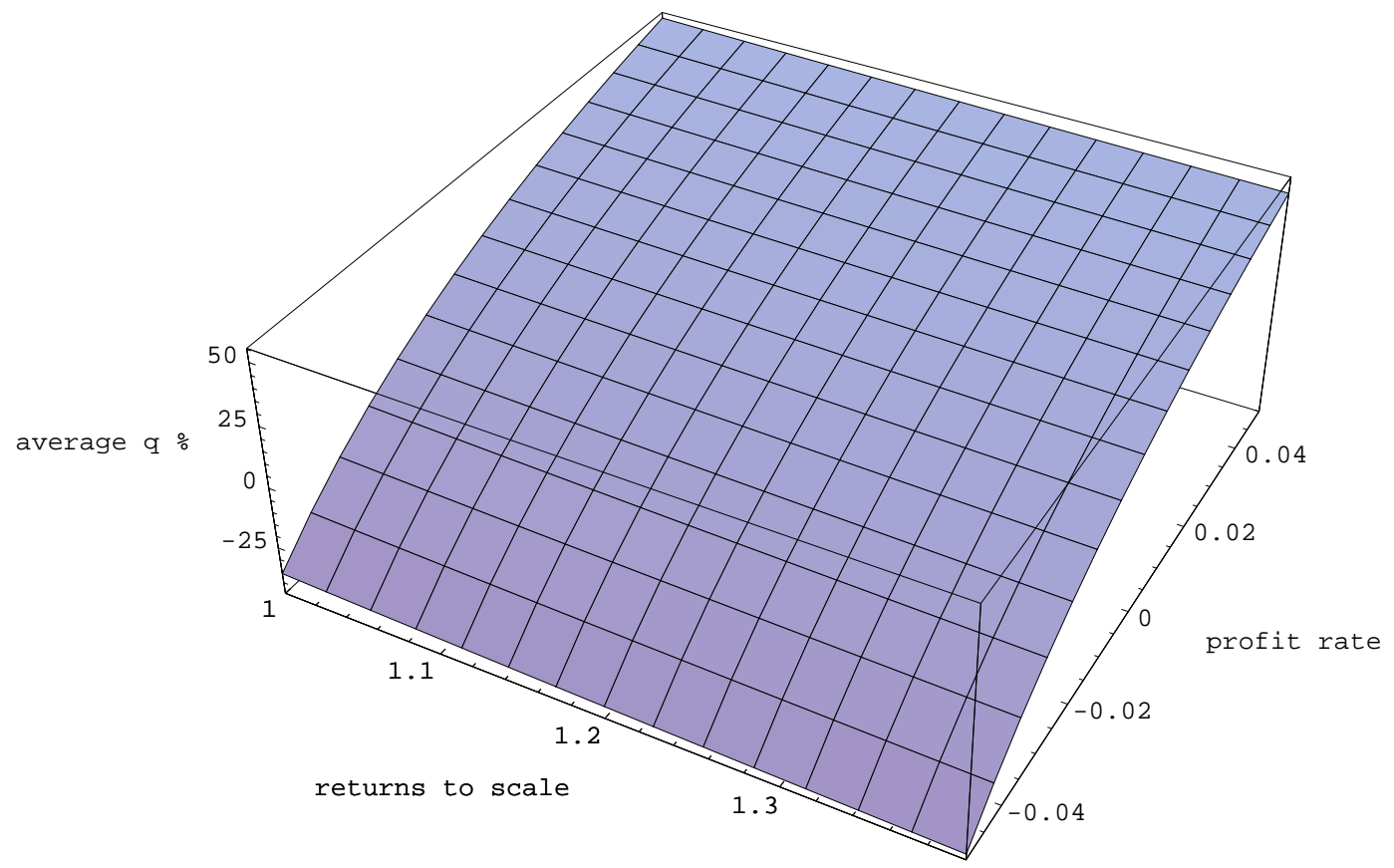

Figure 7: Percent change in average $q$ on impact as a function of scale and profit share



Figure 8: Percent change in investment-output ratio on impact as a function of scale and profit share 


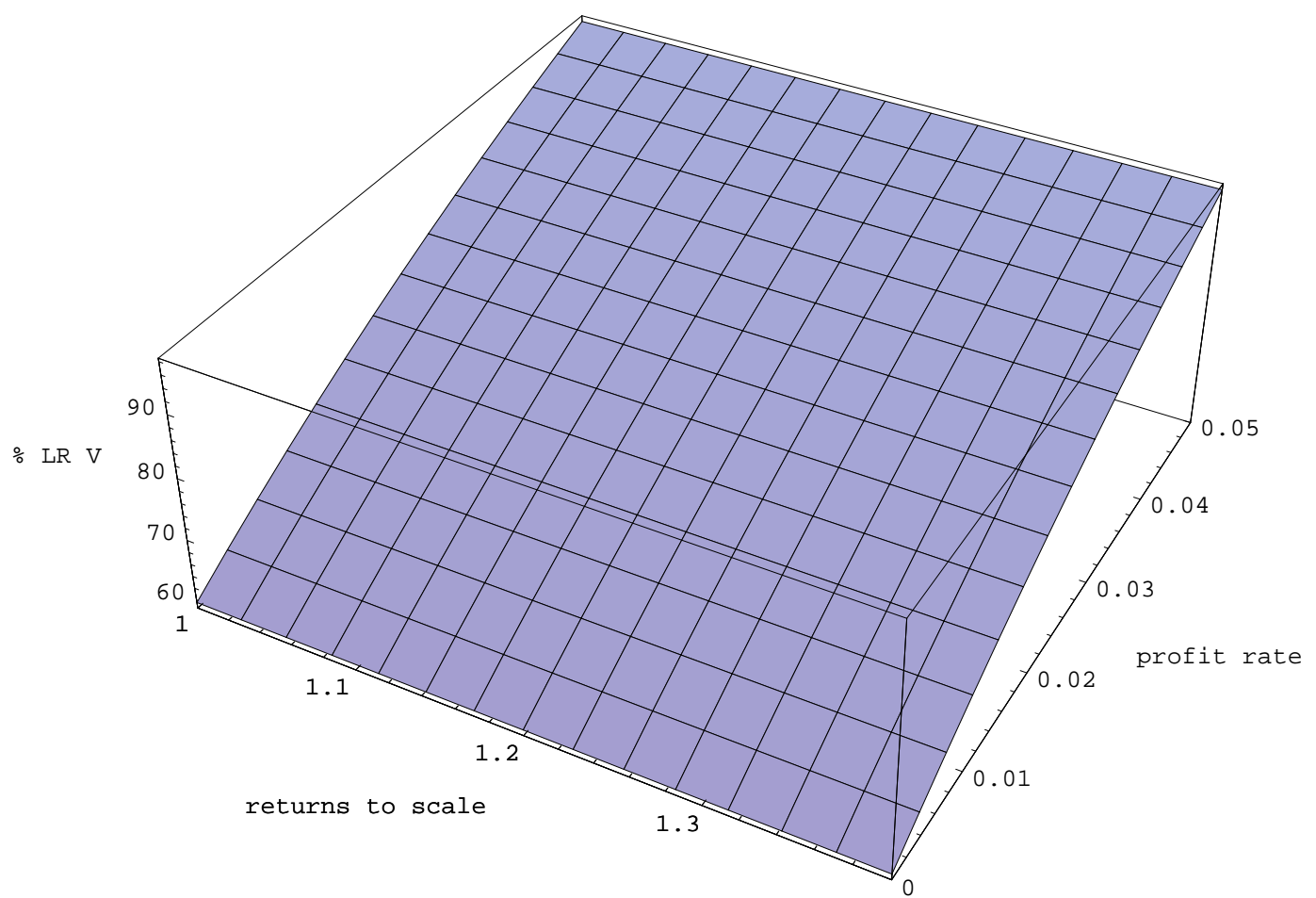

Figure 9: Percent change in long-run value of equity as a function of scale and profit share
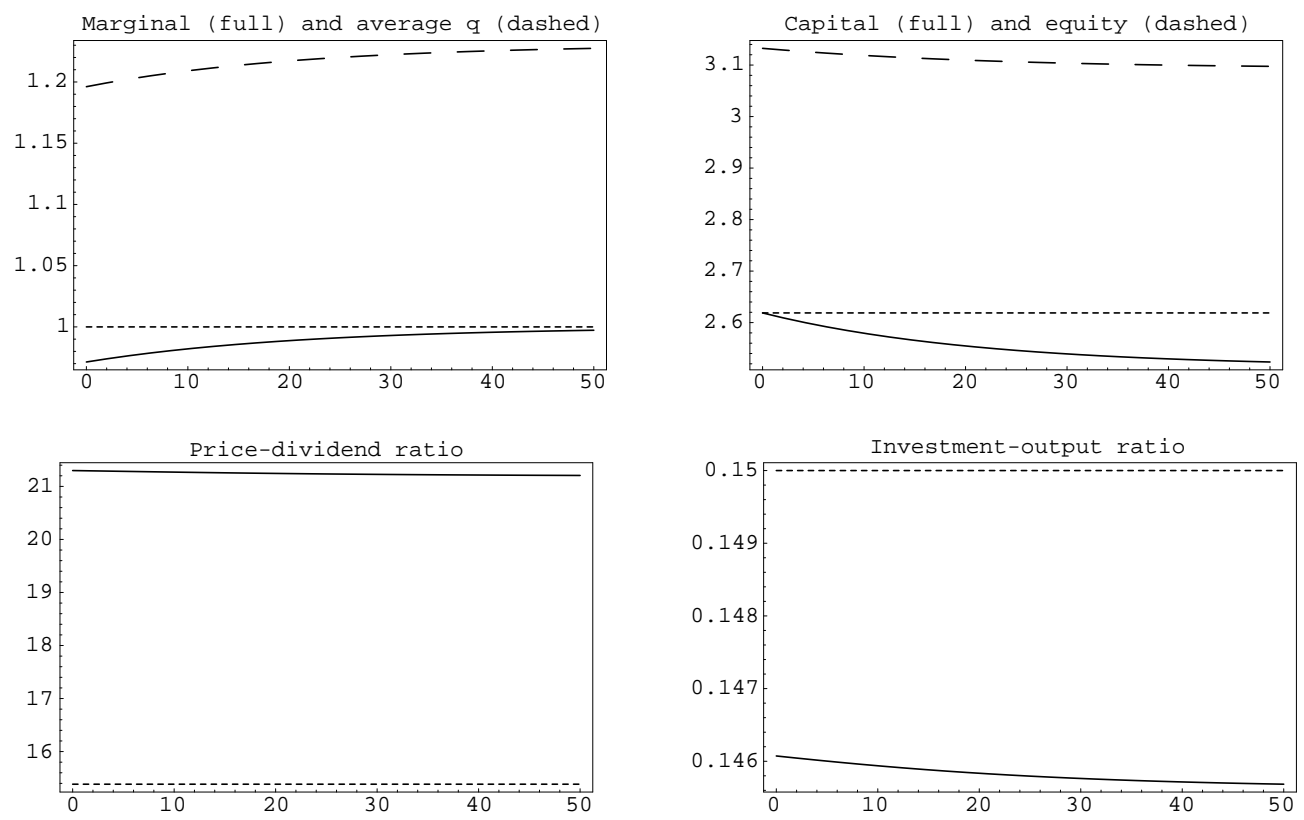

Figure 10: Impulse response - sudden permanent profit share $(\mu=1.03, \eta=1)$ 

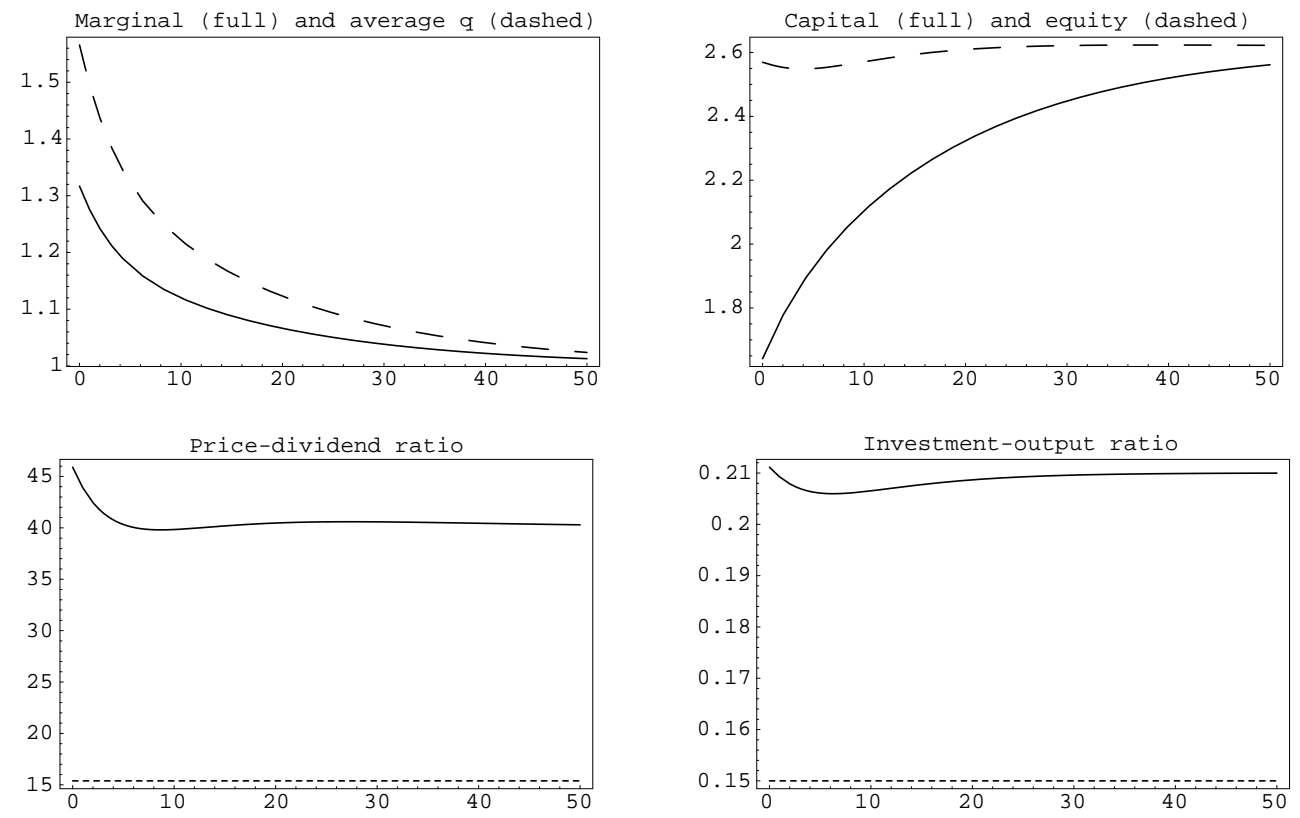

Figure 11: Impulse response - drop in the required return to $r=4 \%$ with scale of $\eta=1.4$ and speed of entry of $\phi=0.3$

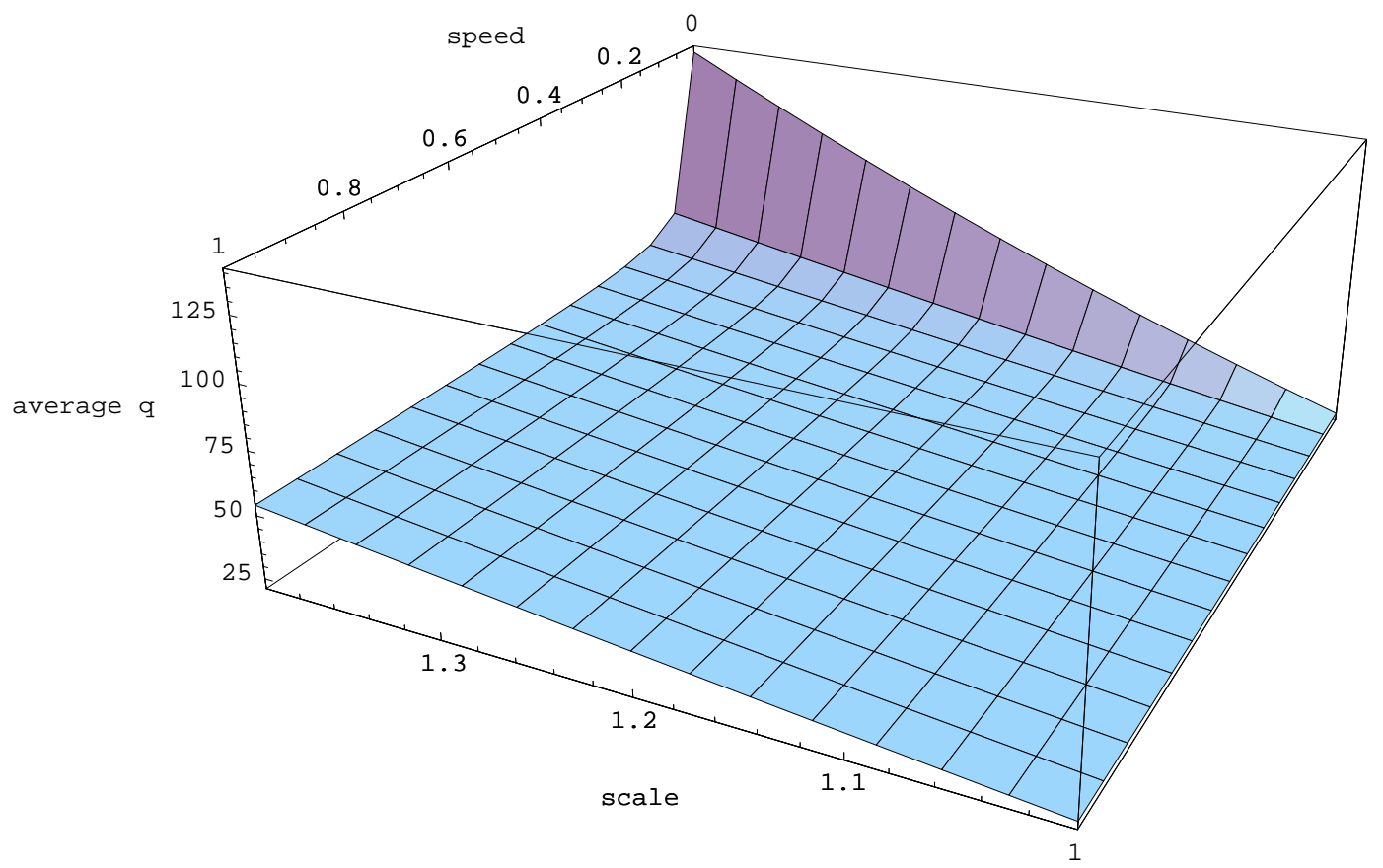

Figure 12: Average $q$ on impact as a function of scale and speed of entry 


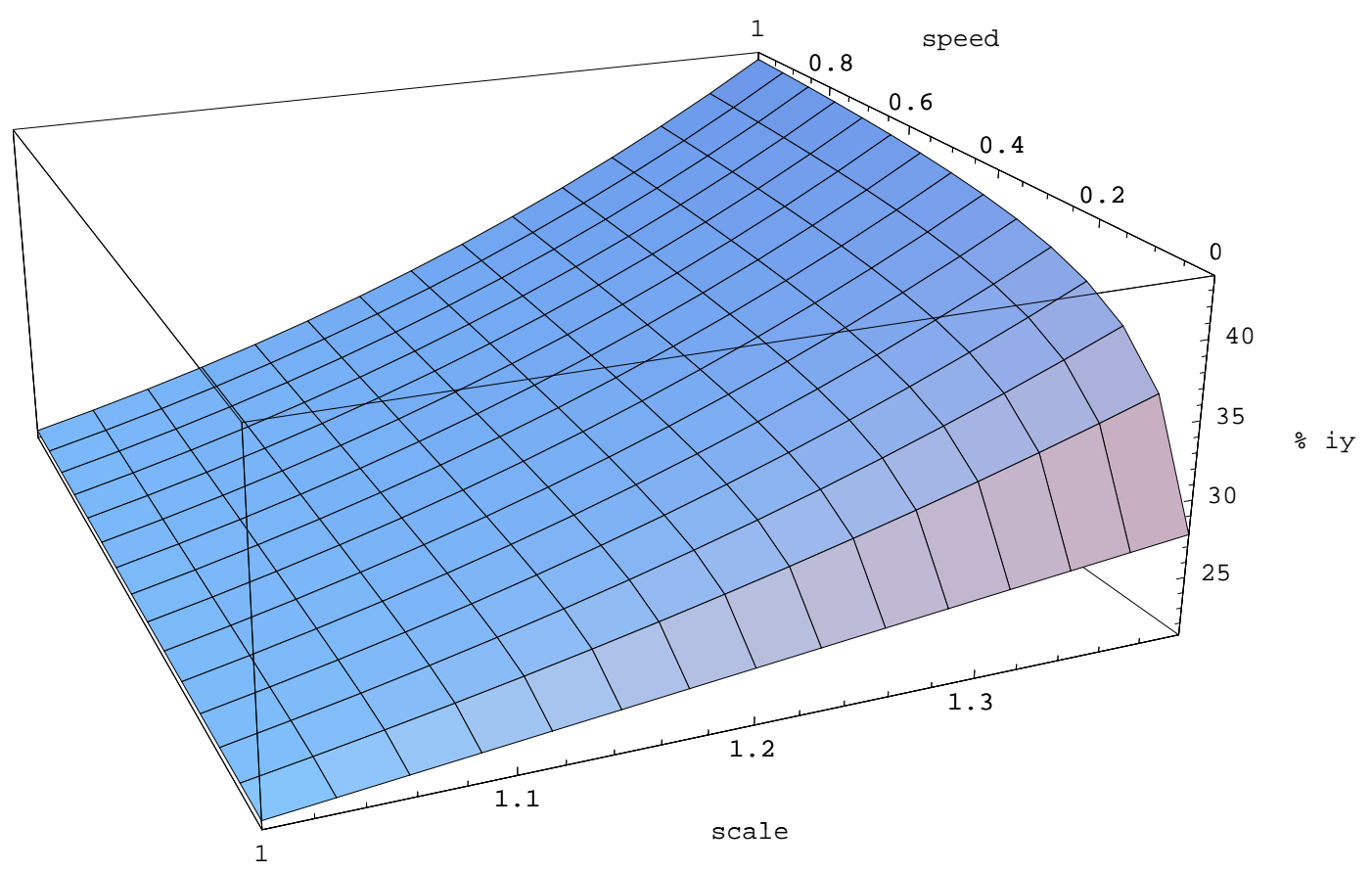

Figure 13: Percentage change in investment ratio on impact as a function of scale and speed of entry
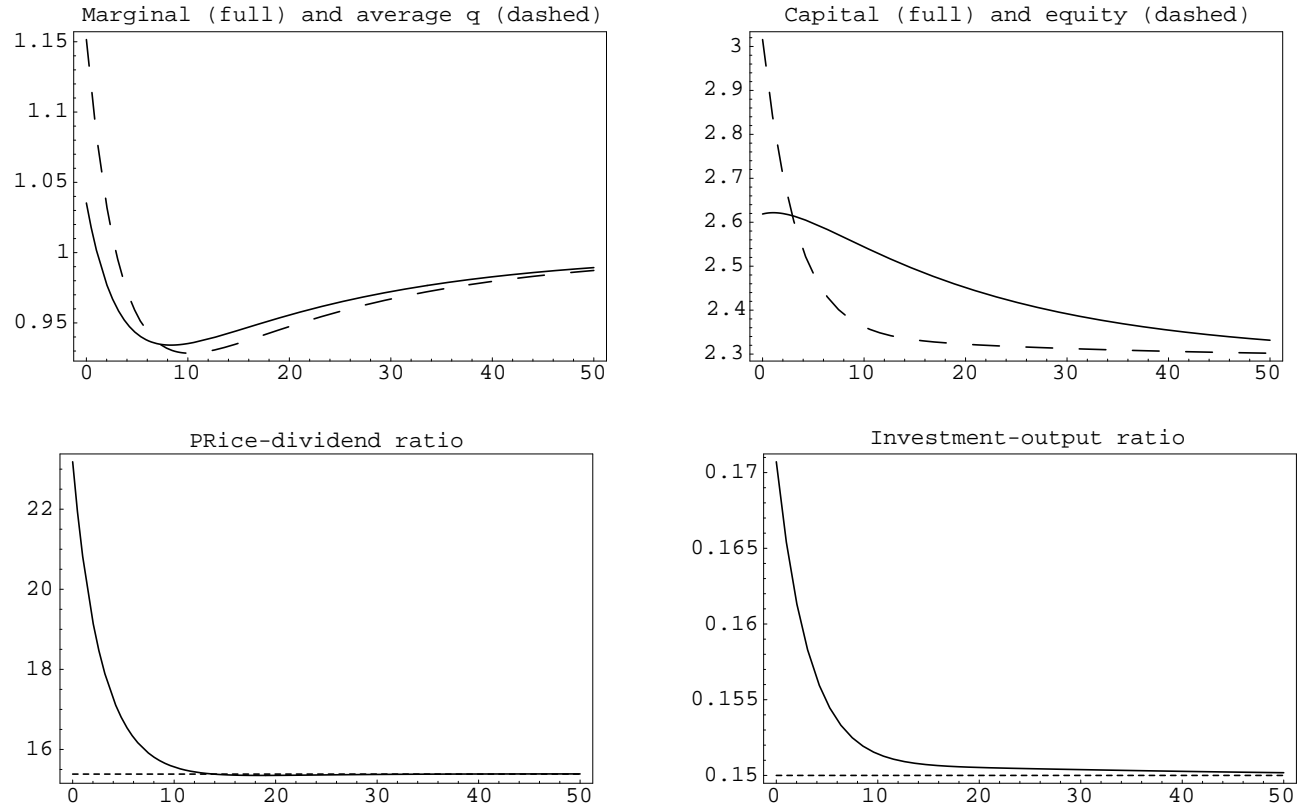

Figure 14: Impulse response - sudden profit share $(\mu=1.1, \eta=1)$ with entry speed $\phi=0.3$ 


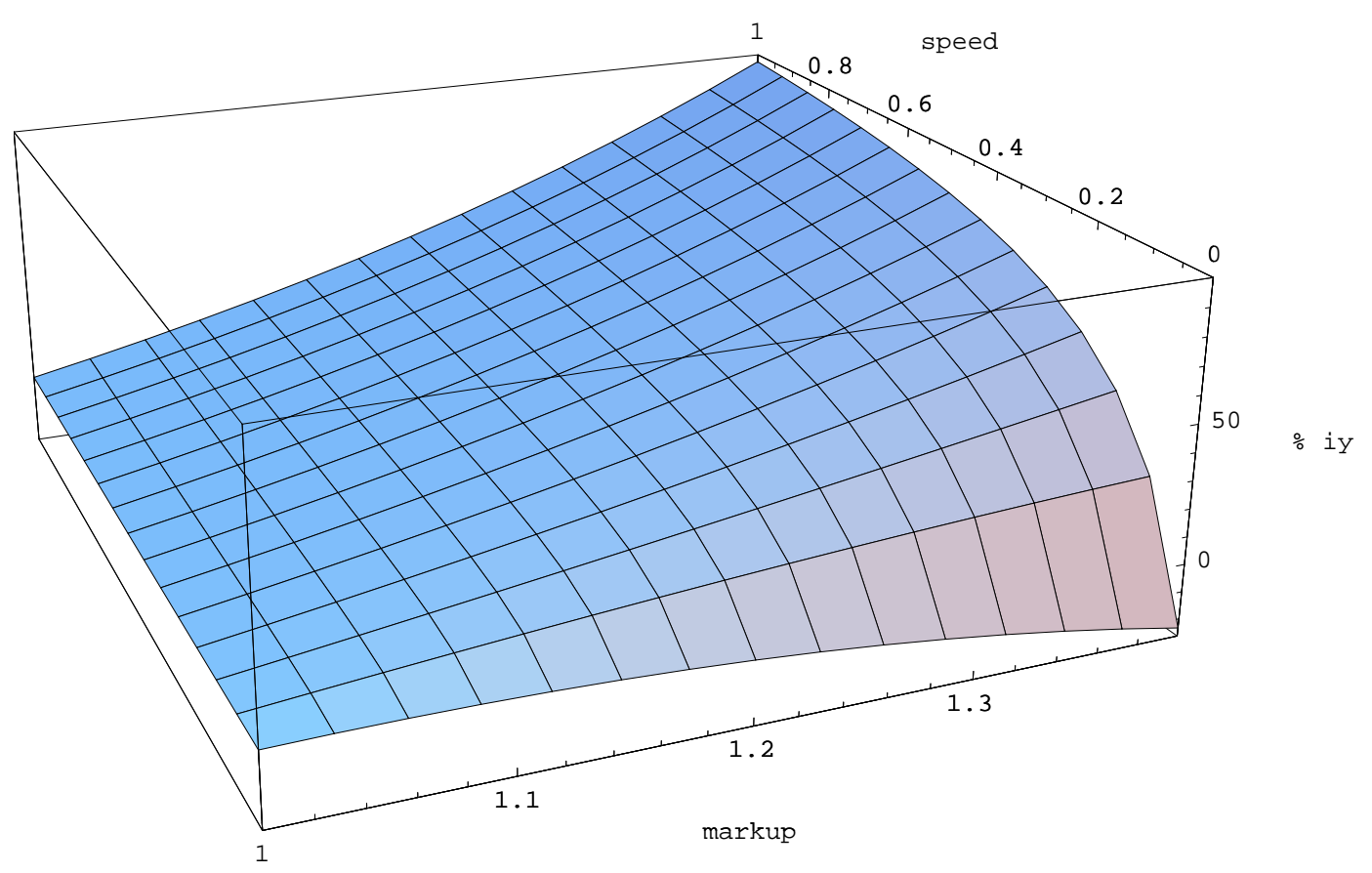

Figure 15: Percentage change in investment ratio on impact as a function of a markup change and speed of entry
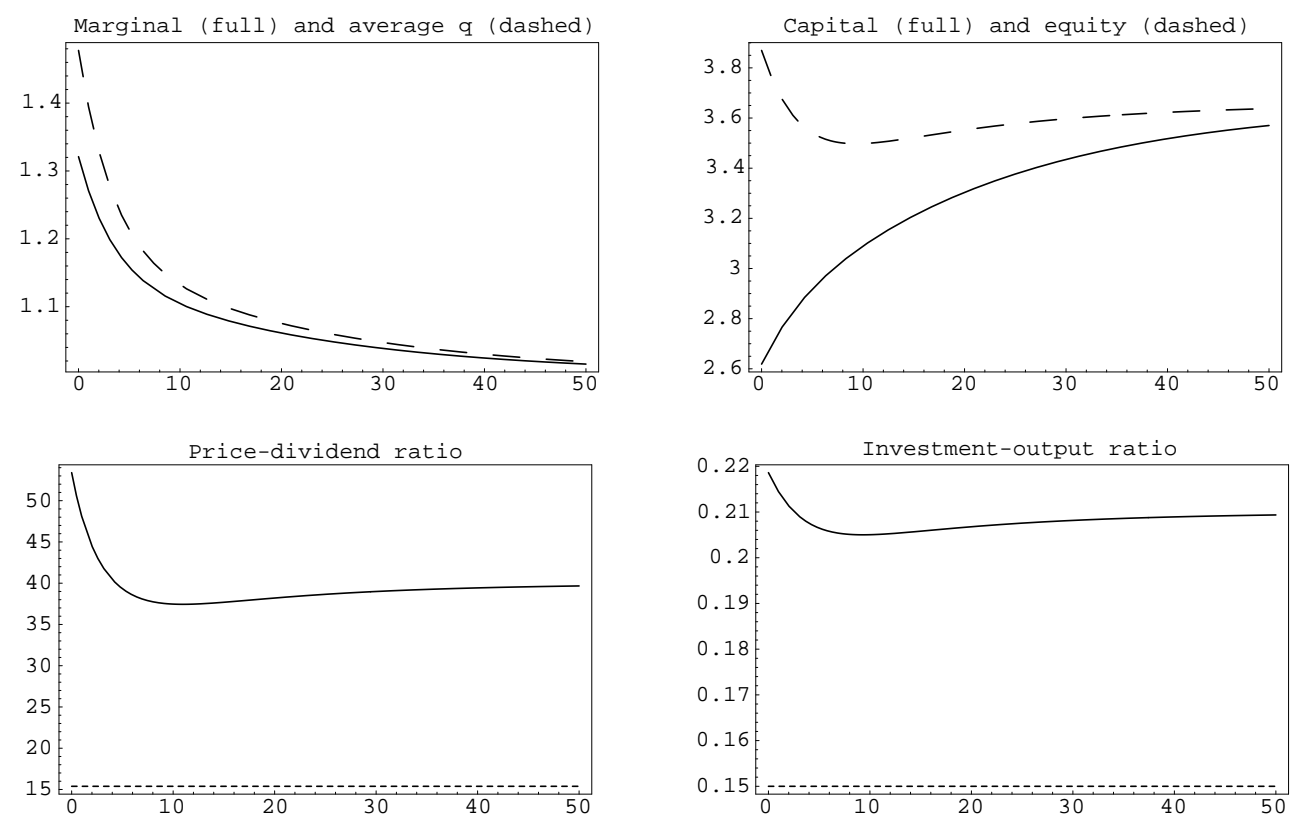

Figure 16: Impulse response - drop in required return to $r=4 \%$ with sudden profit share $(\mu=1.1, \eta=1)$ and entry speed $\phi=0.3$ 


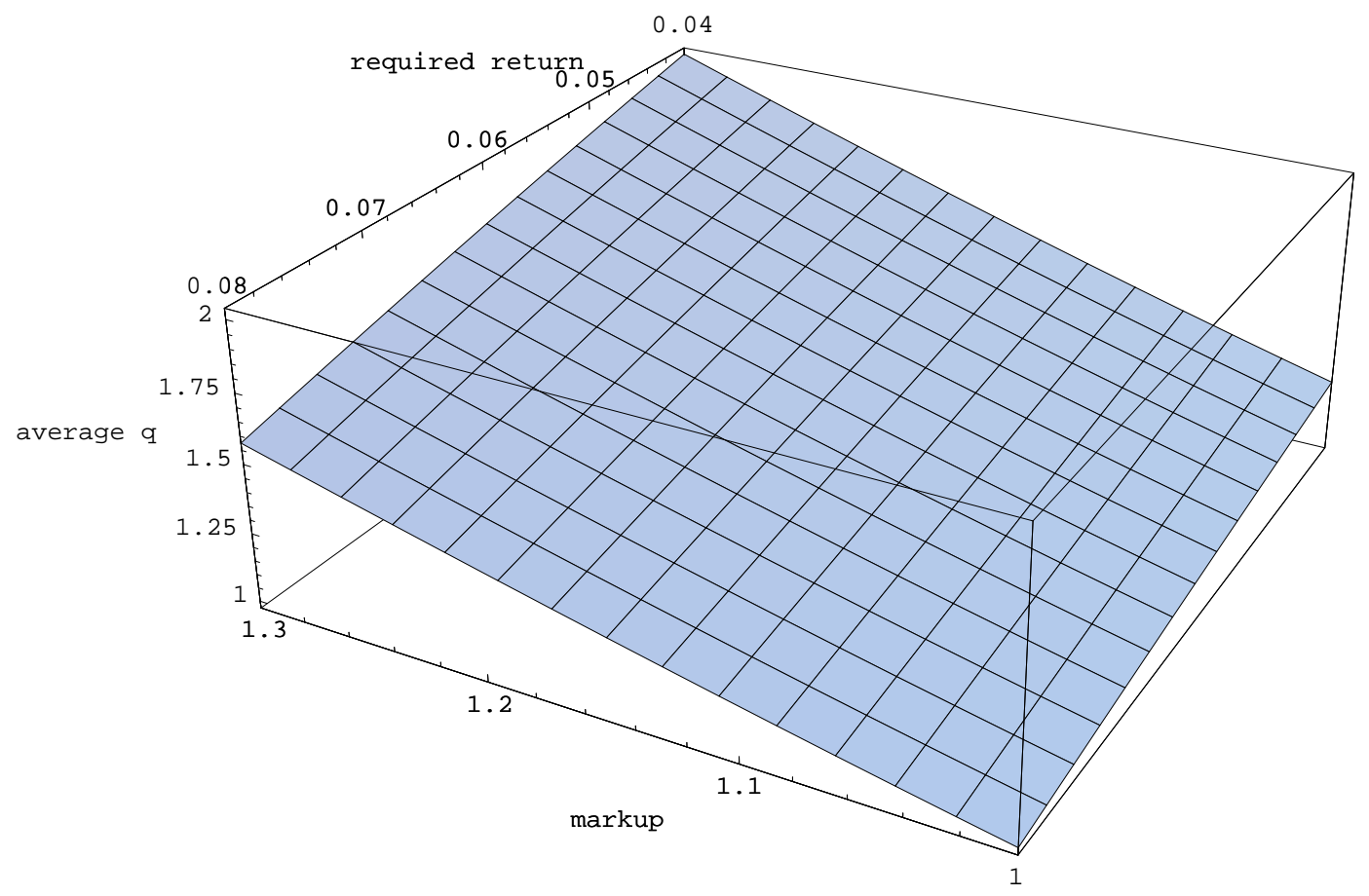

Figure 17: Average $q$ on impact as a function of markup and required return, with entry speed $\phi=0.3$

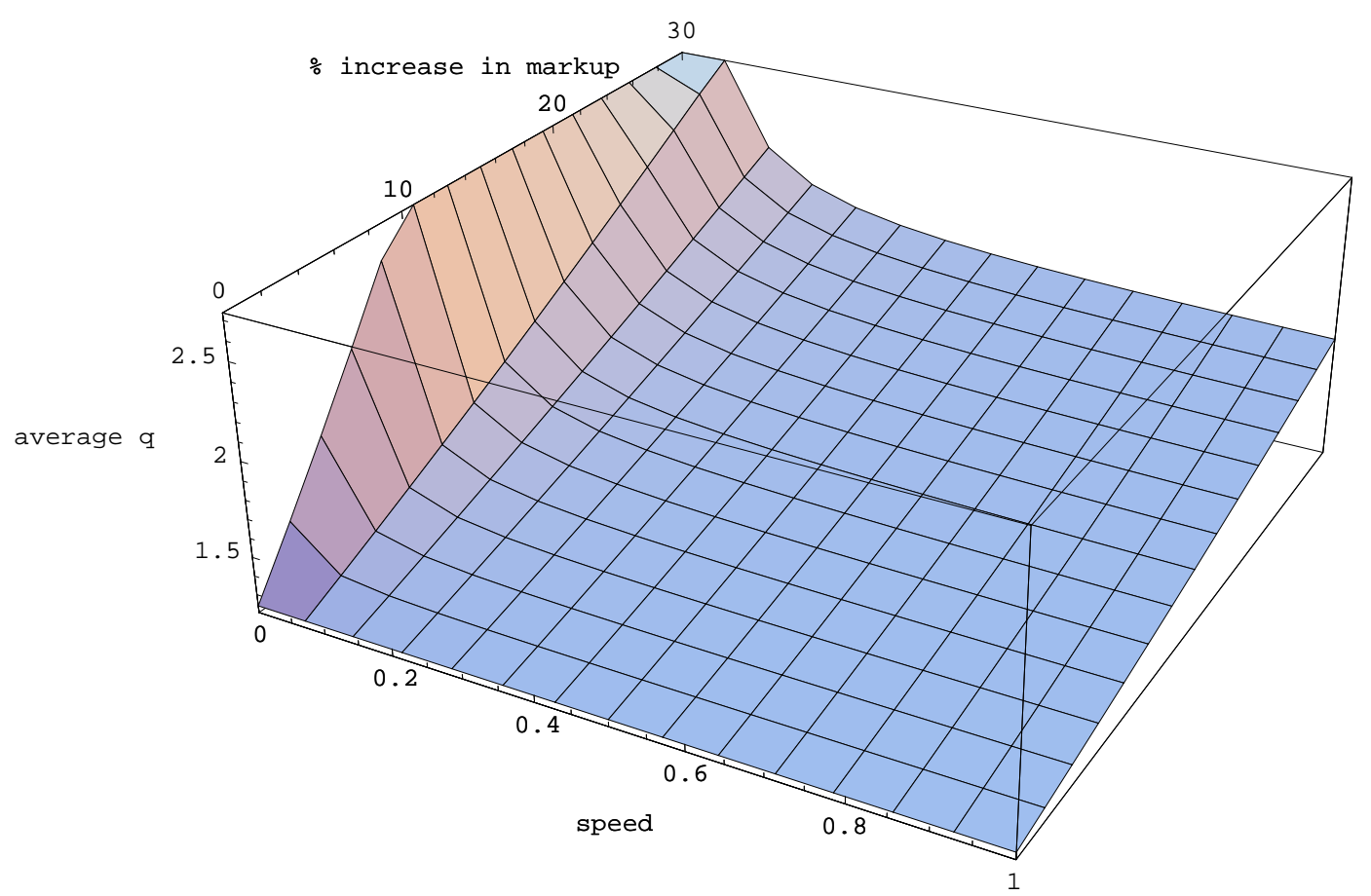

Figure 18: Average $q$ on impact as a function of markup and speed of entry 


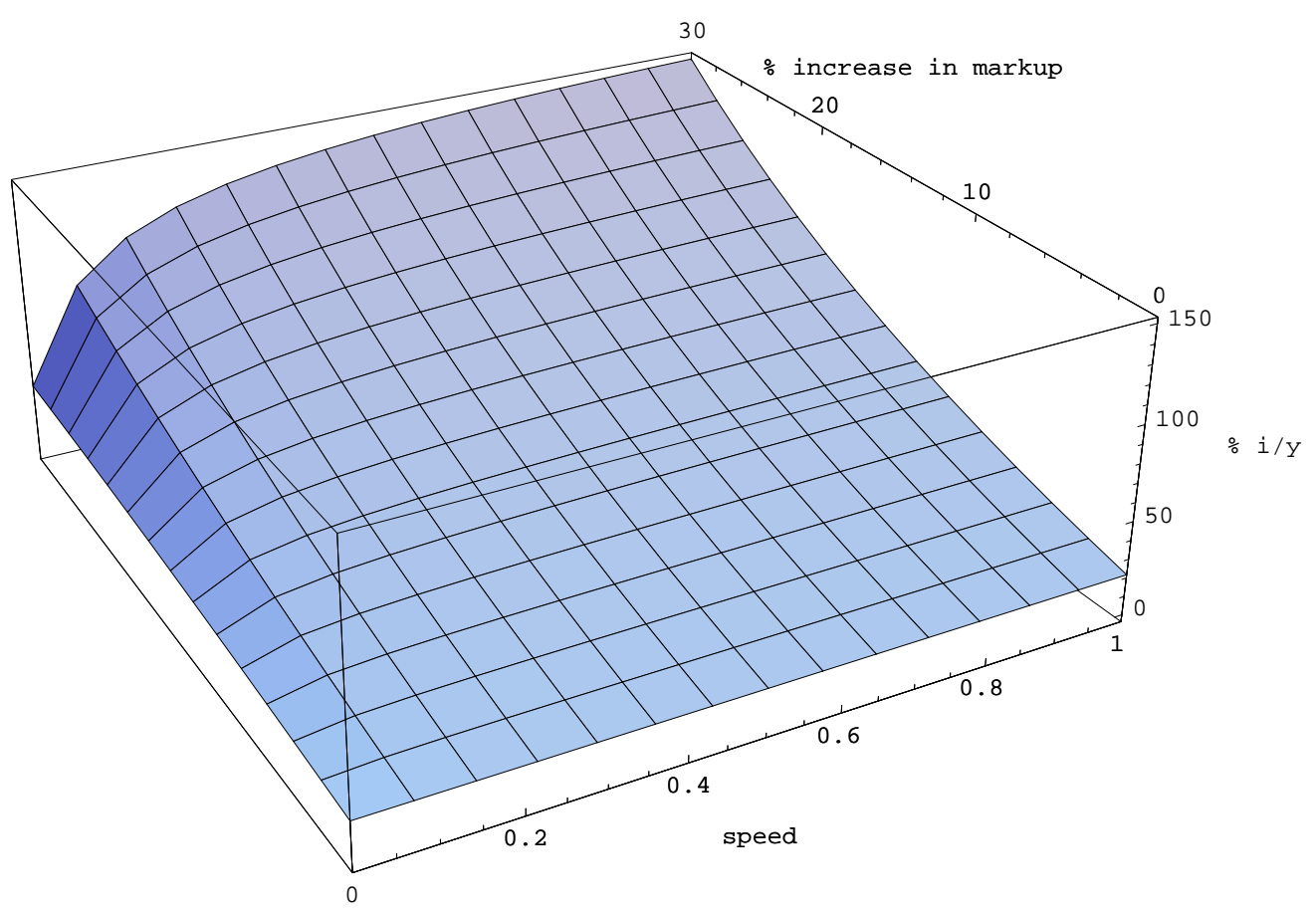

Figure 19: Percentage change in investment ratio on impact as a function of markup and entry speed

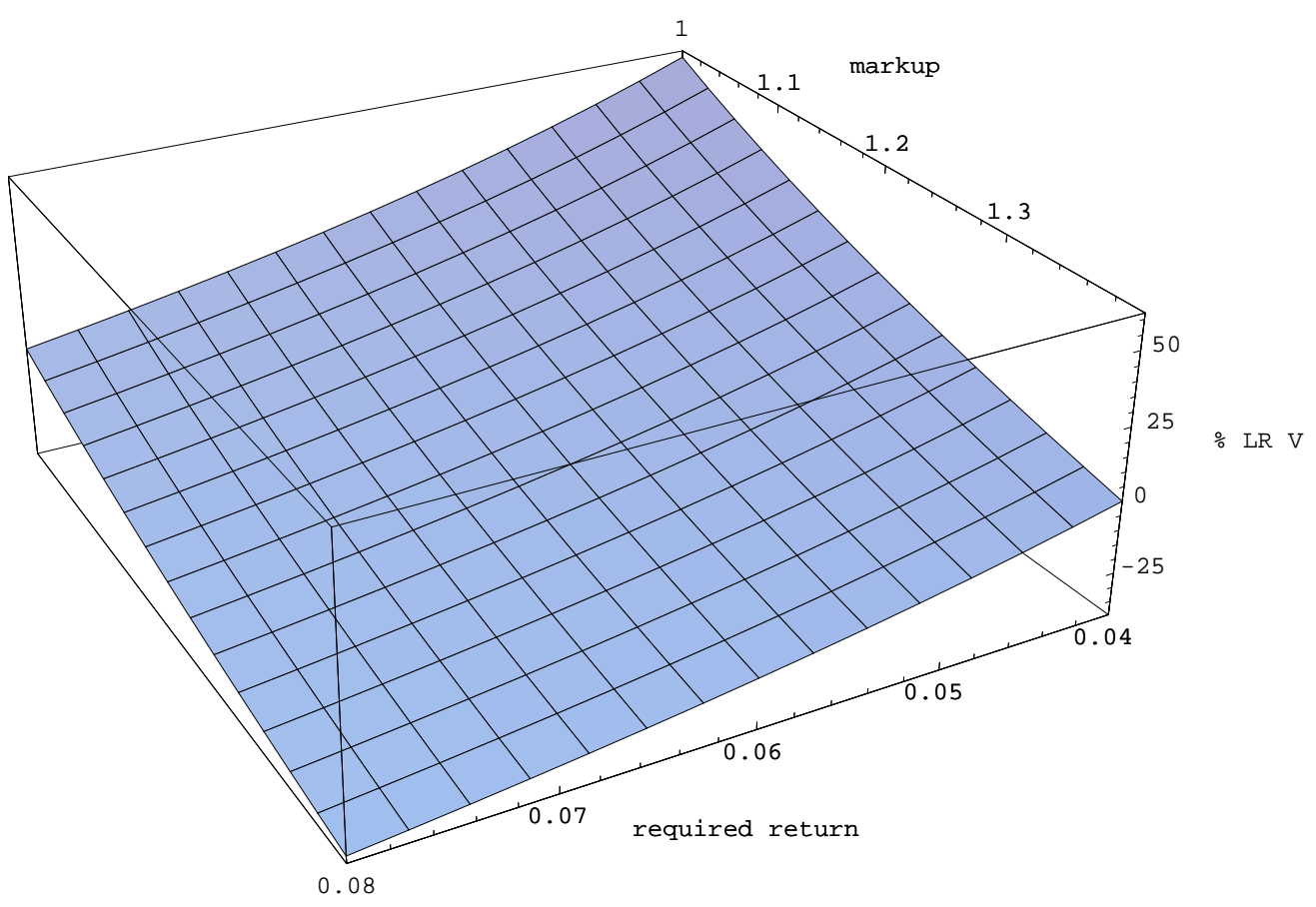

Figure 20: Percentage change in long-run value of equity as a function of required return and markup 